Debate/Debate

\title{
Ainda a Questão dos Sujeitos Pré-verbais em PE: uma Resposta a Costa (2001)
}

\author{
(Pre-verbal Subjects in EP: a Reply to Costa (2001))
}

Pilar P. BARBOSA

(Universidade do Minho, Portugal)

\begin{abstract}
This article examines the arguments put forward in Costa 2001 against the idea that preverbal subjects do not A-move to Spec-IP in European Portuguese (EP). It is argued that the counter-arguments presented by Costa rely on assumptions that do not survive closer scrutiny. Even though the claim that pre-verbal subjects do not occupy the canonical position might appear counter-intuitive, it has the advantage of being part of a general theory of the Null Subject Parameter that is rather simple and yet has the ability to predict a wide range of phenomena regarding preverbal subject constructions in EP as well as in the other Romance Null Subject Languages. The standard theory might appear more intuitive, but makes none of these predictions and has trouble dealing with the same range of phenomena.
\end{abstract}

KEY-WORDS: subject; preverbal; post-verbal; left-dislocation; null subject languages; A-bar movement; predication.

RESUMO: Este artigo examina os argumentos de Costa 2001 contra a proposta de que os sujeitos não se elevam por movimento A para Spec-IP em Português Europeu (PE) e defende que nenhum deles infirma a referida proposta. Apesar de esta parecer, à partida, contra-intuitiva, tem a enorme vantagem de se integrar numa teoria do Parâmetro do Sujeito Nulo, que, sendo extremamente simples, tem um alcance empírico considerável. Em particular, é capaz de predizer não só o leque de propriedades classicamente atribuídas às Linguas de Sujeito Nulo como uma série de outros fenómenos que, à partida, nenhuma outra teoria é capaz de prever. A teoria que defende que os sujeitos ocupam a posição canónica pode parecer mais intuitiva, mas tem uma capacidade preditiva pobre e exige uma série de assunçôes adicionais para lidar com os fenómenos referidos. PALAVRAs-CHAVE: sujeito; pré-verbal; pós-verbal; deslocação à esquerda; línguas de sujeito nulo; movimento A-barra; predicação. 


\section{Introdução}

No artigo intitulado 'Spec,IP ou Deslocado? Prós e contras das duas análises dos sujeitos pré-verbais', João Costa procura fazer uma avaliação das duas análises dos sujeitos pré-verbais em Português Europeu (PE) em debate na literatura recente: a análise tradicional, por si defendida, segundo a qual os sujeitos pré-verbais se elevam por movimento A para Spec-IP, e a análise por mim proposta em Barbosa (1995, 1996a,b, 2000), de acordo com a qual não há movimento A do sujeito para Spec-IP em PE como nas línguas românicas de sujeito nulo. $\mathrm{O}$ balanço entre as duas análises feito por Costa consiste na apresentação do que são consideradas pelo autor as "vantagens" e "desvantagens" de cada uma das análises. O autor conclui que "ambas são necessárias para o PE, embora a adopção de uma das duas posições seja problemática por não explicar resultados categóricos de testes”.

Que as sequências SVO em línguas de Sujeito Nulo (LSN) podem, em princípio, ser potencialmente ambíguas entre uma análise com o sujeito na posição canónica e uma análise em que o aparente sujeito está deslocado e é redobrado pelo sujeito nulo não é um dado novo. É sabido que os sujeitos, tal como os objectos, podem estar deslocados. Esta configuração é claramente visível numa língua como o francês, como se indica a seguir:

(1) a. Pierre il aime la musique.

b. Pierre aime la musique.

(1a) contém um sujeito deslocado e (1b) contém um sujeito canónico. Em face disto, não há como impedir a seguinte configuração numa LSN como o PE:

(2) $\quad[\mathrm{O} \text { Pedro }]_{\mathrm{i}}\left[_{\mathrm{IP}}\right.$ pro $_{i}$ adora música $]$

Uma vez que a gramática do português admite sujeitos nulos, não há forma de garantir que (2) não seja gerada. Assim, a frase $O$ João adora música é apriori potencialmente ambígua entre uma representação equivalente a (1a), com deslocação, e outra equivalente a (1b) com o sujeito na posição canónica:

$$
\left.\left.\mathfrak{L}_{\text {IP }}[\mathrm{O} \text { Pedro }]_{\mathrm{i}} \text { [adora } v_{\mathrm{i}} \text { música }\right]\right]
$$


Assim, quando Costa afirma que ambas as análises são necessárias para o PE, não está, em boa verdade, a dizer nada que não fosse já tacitamente assumido por todos. Por conseguinte, o que está verdadeiramente em causa não é saber se a frase $O$ Pedro adora música pode ter a representação em (2), porque sabemos que pode, mas sim se tem a representação em (3). Em Barbosa 1995, 1996a,b, 2000 defendi que a resposta a esta pergunta é negativa.

Neste artigo, examino cada um dos contra-argumentos apresentados pelo autor no artigo referido e defendo que nenhum deles constitui um verdadeiro problema para a representação que proponho para as construções SVO em PE; pelo contrário, alguns desses mesmos dados revelam-se problemáticos para a representação canónica. Para além disso, procurarei mostrar que as "vantagens" da teoria que defendo são em maior número do que Costa faz crer no seu artigo e que esta tem uma capacidade preditiva forte, com consequências que se estendem para lá do que à partida seria de esperar. Em particular, tem a capacidade de predizer fenómenos acerca dos quais a teoria tradicional não tem nada a dizer. Por restrições de espaço, não poderei examinar todo o domínio empírico abrangido, pelo que remeterei o leitor para os trabalhos já publicados sobre a matéria e cujos resultados não são mencionados por Costa.

Este artigo está organizado da seguinte forma. Num primeiro momento (secção 2), discutirei os dados que constituíram a motivação inicial para a hipótese de que as construções SVO em PE não são derivadas por movimento do sujeito para Spec-IP: a colocação dos pronomes clíticos em PE. Estes dados parecem-nos fundamentais para um melhor entendimento da discussão posterior. Num segundo momento (secção 3), examinarei uma grande parte dos contra-argumentos apresentados pelo autor e mostrarei que estes não constituem verdadeiros problemas para essa hipótese. $\mathrm{Na}$ secção 4, apresento a minha proposta de explicação para o fenómeno em apreço, que enquadro numa teoria geral da propriedade do Sujeito Nulo. Como veremos, a teoria apresentada permitirá ainda explicar naturalmente mais dois fenómenos que Costa 2001 apresenta como argumentos contra a minha proposta: (i) os padrões de concordância verificados com sujeitos pré e pós verbais (secção 5); (ii) certo tipo de construções de redobro com um pronome realizado lexicalmente (secção 6). 


\section{Os padrões de colocação dos pronomes clíticos em PE}

É sabido que a posição dos pronomes clíticos em PE varia conforme o contexto. Em construções SVO, a próclise é a única opção quando o sujeito é uma expressão não referencial, como 'alguém' ou 'ninguém' (cf. (4)) ${ }^{1}$; a ênclise verifica-se com sujeitos referenciais ou indefinidos específicos (cf. 5)):

(4) a. Ninguém/alguém/algum professor o viu.

b. *Ninguém/alguém/algum professor viu-o.

(5) a. A Maria/ um professor viu-o a entrar na casa do Pedro.

b. *A Maria o viu/um professor o viu entrar na casa do Pedro.

O padrão em (4) é aquele que é observado quando um constituinte interrogativo precede o clítico no interior da oração mínima que o contém:
a. Quem o viu?
b. *Quem viu-o?

Em Barbosa 1993, 1996a, 2000, examino os diferentes padrões de colocação do clítico em PE e concluo que o conjunto de expressões que desencadeia a próclise coincide com o conjunto de expressões que são incompatíveis com a DEC. É sabido que os quantificadores negativos ou sem restrição lexical não podem ser deslocados. Assim, quando consideramos uma lingua como o francês, em que a DEC de sujeito é visível através da realização do redobro pronominal, observamos os seguintes contrastes:

(7) a. Pierre, il n'a rien dit.

(8) a. *Quelq'un il vien.

b. Quelq'un vien.

(9) a. *Personne il n'a rien dit.

b. Personne n'a rien dit.

A impossibilidade de deslocação das expressões que desencadeiam a próclise também é visível em PE, com objectos. Em primeiro lugar, verificamos que a ênclise é o padrão observado na DEC de objecto (cf. 10) e quando um objecto é topicalizado (cf. (11)). A próclise é o padrão observa-

\footnotetext{
1 Para além das expressões quantificadas mencionadas no texto desencadeiam a próclise o quantificador universal (na leitura não grupal), e os DPs que contêm operadores afectivos na acepção de Klima (1964), como os operadores de foco só e mesmo. Em nossa opinião, a gama de expressões que desencadeia a próclise corresponde aos QPs não grupais de Beghelli e Stowell 1997. Para uma discussão das propriedades destas expressões, consultar Martins 1994.
} 
do na anteposição de quantificadores negativos ou indefinidos não específicos (cf. (12):

(10) Esses livros, dei-os/*os dei à Maria.

(11) Esses livros, dou-te/* te dou, se quiseres.

(12) a. Alguma coisa lhe disseram/*disseram-lhe, mas não sei o quê.

b. Nenhuma resposta me deram/*deram-me até hoje.

Em segundo lugar, observamos que as expressões quantificadas que exigem a próclise são incompatíveis com a DEC:

(13) a. *Alguma coisa a disseram, mas não sei o quê.

b. *Nenhuma resposta ma deram até hoje.

Os dados em (7-12) têm uma explicação simples: uma vez que estas expressões não têm valor referencial, não podem ser usadas como tópicos discursivos nem podem estabelecer uma relação de co-referência com o redobro pronominal, isto é, nem podem ser topicalizadas nem ocorrer em DEC. Nos trabalhos referidos, adopto a análise da DEC de Chomsky 1977, I. Duarte 1987, Iatridou 1991, Raposo 1996, segundo a qual os DPs em DEC são gerados na base numa posição de adjunção, podendo ocorrer em adjunção a CP ou IP:

(14) Adjunção a $C P$ :

Este livro $_{\mathrm{I}}$ [ $_{\mathrm{CP}}$ quando é que $\mathrm{O}_{\mathrm{I}}$ vais ler $]$ ?

(15) Adjunção a IP:

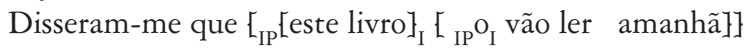

No que se refere à topicalização, adopto a análise de Raposo 1996 segundo a qual o tópico também é gerado na base numa posição de adjunção e o que se move é um operador nulo ${ }^{2}$ :

(16) Topicalização: $[\mathrm{DP}]_{\mathrm{k}}\left[_{\mathrm{CP} / \mathrm{IP}} O p_{\mathrm{k}}\left[\mathrm{V} \mathrm{t}_{\mathrm{k}} \ldots\right]\right]$

(17) [O livro] $\mathrm{L}_{\mathrm{CP} / \mathrm{IP}} O p_{\mathrm{k}}\left[\right.$ dou-te $\mathrm{t}_{\mathrm{k}}$ amanhã $\left.]\right]$

Para Raposo, tanto a DEC como a Topicalização envolvem um tópico gerado na base numa posição de adjunção a IP ou CP. O tópico é interpretado por "regras de predicação" sendo que IP ou CP contém uma posição

2 I. Duarte 1987, no seu estudo detalhado da topicalização, propõe também que a topicalização envolve adjunção a CP ou IP, embora rejeite a ideia de que há movimento de um operador nulo. 
"aberta", necessária para que o constituinte oracional possa ser interpretado como um predicado. O que distingue Topicalização da DEC é o movimento do operador nulo (cf. também Chomsky 1977). Na DEC, não há movimento na sintaxe: o clítico fornece a posição 'aberta' necessária para que o elemento deslocado seja interpretado como sujeito da predicação complexa (cf. I. Duarte 1987, Iatridou 1991).

Reconsideremos agora os exemplos com expressões quantificadas não referenciais, como (12). Estes são semelhantes aos exemplos com extracção de constituintes interrogativos, que também são incompatíveis com um clítico e exigem a próclise:

(18) *Que resposta ta deram?

Por esta razão, em Barbosa (1993) propus que (12a,b) envolvem extracção (isto é, movimento A-barra) do objecto (veja-se também Martins (1994) e Raposo (1994)):

(19) Anteposição de expressões quantificadas não referenciais (EQNR):

$\left[_{C P} \operatorname{EQNR}\left[{ }_{I}, \mathrm{~V} \quad\left[\begin{array}{lll}\mathrm{t} & ]\end{array}\right]\right.\right.$

Desta forma, podemos reduzir os contextos de ocorrência da próclise e da ênclise em frases raiz com um objecto em posição inicial às seguintes configurações (em (20A) deixamos em aberto a possibilidade de as frases raiz não projectarem um $\mathrm{CP}$, mas essa questão não é crucial para a questão em apreço):

(20) Configurações sintácticas e colocação do clítico em frases raiz

\begin{tabular}{|c|c|c|c|c|}
\hline A & $\begin{array}{l}\text { DEC } \\
\text { Topicalização }\end{array}$ & V-cl & [ $\mathbf{X P}$ ] [CPIIP & $\mathrm{V}$ cl $]$ \\
\hline B & $\begin{array}{l}\text { Movimento de expressões não referenciais } \\
\text { Movimento QU }\end{array}$ & cl-V & {$\left[_{C P} \mathbf{X P}_{\mathbf{I}} \mathbf{c l ~ V}\right.$} & ] \\
\hline
\end{tabular}

Reconsideremos agora os sujeitos. Vimos acima que as expressões que desencadeiam a próclise enquanto sujeitos são as mesmas que são incompatíveis com a DEC. Isto levanta as seguintes questões: (i) por que razão há esta correlação? (ii) se os sujeitos pré-verbais se movem para a posição canónica, como podem ser explicadas as diferenças entre os dois tipos de 
expressões? A conclusão lógica a tirar destes factos é a seguinte: contrariamente ao que sucede em francês, em que existem duas opções - sujeito em Spec-IP, sujeito deslocado - em PE, a primeira opção não existe. Os sujeitos pré-verbais têm apenas duas alternativas: ou estão em posição de DEC sendo redobrados por uma categoria vazia em posição argumental, pro, à qual corresponde a ênclise; ou, se fazem parte do conjunto de expressões que não podem ser deslocadas, são movidos para a posição pré-verbal por movimento A-barra, configuração que corresponde à próclise (para detalhes sobre a análise, consultar Barbosa 1996a, 2000). Sendo assim, (21a) tem a estrutura ilustrada em (21b) e (22a) tem a estrutura (22b) (na representação em (21b), assumimos que pro ocorre dentro do VP, na posição em que é gerado na base; porém, esta assunção não é crucial para o a discussão em apreço, pelo que pedimos ao leitor para não dar demasiada importância a esta componente da análise, que será desenvolvida na secção 4; da mesma forma, em (22b) utilizamos o termo neutro FP para designar a projecção funcional que serve de ponto de chegada ao movimento do quantificador; para efeitos da presente discussão, basta perceber que, em (22b), o quantificador ocupa uma posição interna a $\mathrm{CP}$ ):

(21) a. A Maria viu-o.

b. $[\text { A Maria }]_{i}\left[_{\mathrm{CP} / \mathrm{IP}}\right.$ viu-o pro $\left.{ }_{\mathrm{i}}\right]$

a. Ninguém o viu.

b. $\left[_{\mathrm{FP}}[\right.$ Ninguém $]$ o viu $\left.t\right]$

Esta hipótese tem a enorme vantagem de reduzir drasticamente os contextos indutores de próclise e ênclise: (21b) é configuracionalmente idêntica à estrutura apresentada na coluna direita de A em (20); (22b) reduz-se a B. Desta forma, chegamos à seguinte simplificação dos contextos indutores de ênclise e próclise nos exemplos até aqui mencionados:

\begin{tabular}{|c|c|c|c|}
\hline A & V-cl & [ $\mathbf{X P}$ ] [ & $\mathrm{V}$ cl \\
\hline B & cl-V & ${ }_{\text {СP }} \mathbf{X P} \mathbf{c l} \backslash$ & $.]$. \\
\hline
\end{tabular}

(23), por sua vez, permite formular a seguinte generalização acerca da distribuição da ênclise e da próclise em PE: 
(24) Ênclise sse nenhum elemento com matriz fonética precede o complexo ver bal no interior do CP mínimo que o contém (ou IP, sse CP não projecta), i.e., no interior da Fase (Chomsky 1999). Próclise em todos os outros casos.

O contexto indutor de ênclise descrito em (24) abrange tanto a configuração ilustrada na coluna direita de A em (23) como as construções em que o complexo verbal ocupa a posição inicial absoluta (por exemplo, Vimolo ontem): em ambos os casos, o complexo verbal não é precedido por nenhum elemento com matriz fonética no interior do CP mínimo que o contém (ou IP, sse CP não projecta) ${ }^{3}$. (24) é simplesmente uma descrição dos contextos em que ocorre um e outro padrão. Podemos formular várias teorias para explicar este fenómeno. Em Barbosa 1993, 1996, 2000 propus que (24) se deve a restrições de ordem prosódica impostas à realização morfológica do próprio clítico. Martins 1994, Costa e Martins 2004, Uriagereka 1995, Raposo e Uriagereka (2005) atribuem estas alternâncias a restrições impostas à realização morfológica de um núcleo funcional nulo situado entre $\mathrm{C}$ e T. Os detalhes de cada análise, contudo, são irrelevantes para a discussão em causa. O que verdadeiramente interessa é que pudemos transformar um problema verdadeiramente complexo numa generalização simples que pode servir de ponto de partida para a formulação de hipóteses explicativas ${ }^{4}$.

Por outro lado, a teoria que assume que os sujeitos ocupam a posição canónica não tem forma de explicar o diferente comportamento dos dois tipos de sujeitos a não ser através da ideia de que os sujeitos não referenciais quantificados juntamente com os constituintes QU, complementadores, a partícula da negação e certo tipo de advérbios "atraem" o clítico (Frota e Vigário 1996, I. Duarte 2003). Contudo, esta proposta enfrenta problemas de difícil solução, entre os quais o facto de poder existir uma grande distância entre o atractor e o clítico, como se exemplifica a seguir:

(25) Disseram-me que os alunos que a Maria reprovou se foram queixar ao Director de Curso.

\footnotetext{
3 Em Barbosa 2000 defende-se que os advérbios indutores de ênclise estão numa posição de adjunção a IP ou CP, isto é, ocorrem em estruturas analisáveis como em A de (23).

4 Convém salientar que todas as teorias mencionadas implicam a assunção de que as expressões que desencadeiam a próclise ocupam uma posição estrutural diferente daquelas que desencadeiam a ênclise. Isto significa que todas elas terão de explicar por que razão a posição dos sujeitos varia conforme as suas propriedades referenciais.
} 
Uma vez feita a descrição da principal motivação empírica exclusiva do PE para a análise proposta, passo ao exame das objecções de Costa (2001).

\section{Os contra-argumentos de Costa (2001)}

Nesta secção, examinamos a maior parte dos contra-argumentos de Costa colocando-nos numa perspectiva neutra do ponto de vista explicativo. Isto é, procuraremos mostrar que, independentemente da explicação teórica que se encontre para as posições do sujeito em PE, os argumentos apresentados por Costa em favor da ideia de que o sujeito se move para Spec-IP em estruturas SVO não são isentos de problemas. Os argumentos que examinamos nesta secção podem ser agrupados em quatro classes diferentes. A primeira classe inclui argumentos que se baseiam na ideia de que a deslocação envolve movimento A-barra. Esta assunção, porém, não está em conformidade com um dos aspectos fundamentais da hipótese avançada na secção anterior, que é precisamente a distinção estrutural entre deslocação e movimento A-barra. A segunda classe é constituída por argumentos construídos em torno do pressuposto de que os sujeitos em DEC têm as mesmas propriedades prosódicas, informacionais e até distribucionais dos objectos em DEC. Como veremos, este pressuposto não sobrevive a um estudo mais cuidadoso do que são as propriedades da DEC de sujeito, quer em PE quer em línguas em que esta é morfologicamente visível, como o francês ou o português do Brasil (PB). A terceira classe é heterogénea e será abordada na última parte desta secção.

\subsection{A deslocação à esquerda não é o mesmo que movimento $A$-barra}

\subsubsection{Reconstrução}

Costa observa que o movimento A-barra reconstrói obrigatoriamente, o que não acontece com o movimento A e acrescenta:

Se se assumir que o sujeito pré-verbal está em Spec,IP, espera-se que não haja reconstrução do sujeito, mas que possa haver reconstrução de um complemento deslocado à esquerda. Com efeito, o sujeito pré-verbal em (8a) não pode reconstruir, tomando escopo obrigatório sobre o agente da passiva. $\mathrm{Na}$ frase $(8 \mathrm{~b})$, o complemento pode reconstruir, sendo obtida ambiguidade de escopo: 

a. Três livros foram lidos por dois estudantes.
$\mathrm{S}>\mathrm{Ag} ; * \mathrm{Ag}>\mathrm{S}$
b. Três livros, dois estudantes leram-nos.
$\mathrm{S}>\mathrm{O} ; \mathrm{O}>\mathrm{S}$

O facto de haver ambiguidade com o objecto, mas não com o sujeito, parece mostrar que as posições ocupadas por estes são diferentes.

Esta passagem merece ser examinada com atenção porque se prende com um dos meus principais argumentos em favor da deslocação, baseado precisamente na interpretação de indefinidos. Com efeito, o ponto da minha argumentação é a observação de que exemplos como (8a) (na numeração do texto original de Costa (2001)) são obrigatoriamente interpretados com escopo largo do sujeito. Este facto, contrariamente ao que é afirmado por Costa, não é o esperado se o sujeito está em Spec-IP. Frases equivalentes em inglês são ambíguas, como é sobejamente conhecido, e são-no não por causa da reconstrução, mas porque há subida dos quantificadores. Assim, a frase do inglês correspondente a (8a) tem as duas interpretações indicadas em (26) porque existem duas Formas Lógicas possíveis dependendo da posição relativa dos quantificadores após a elevação:

(26) Three books were read by two students.
a. [three books $\mathrm{x}$, two students $\mathrm{y}$ ] $\mathrm{x}$ was read by $\mathrm{y}$
$(\mathrm{S}>\mathrm{Ag})$
b. [two students $y$, three books $\mathrm{x}$ ] $\mathrm{x}$ was read by $\mathrm{y}$
$(\mathrm{Ag}>\mathrm{S})$

Ora o que é estranho é que o português não evidencie este tipo de ambiguidade. Em Barbosa, uso o seguinte contraste entre o inglês e o português:

(27) Look! A flower is growing in every pot!

a. $[\forall \mathrm{x}: \mathrm{x}$ a pot, $\exists \mathrm{y}: \mathrm{y}$ a flower $] \mathrm{y}$ is growing in $\mathrm{x}$.

b.\# [ $\exists \mathrm{y}$ : $\mathrm{y}$ a flower, $\forall \mathrm{x}$ : $\mathrm{x}$ a pot] $\mathrm{y}$ is growing in $\mathrm{x}$.

(28) Olha! Está uma flor a crescer em todos os vasos!

a. $[\forall \mathrm{x}$ : $\mathrm{x}$ a pot, $\exists \mathrm{y}$ : $\mathrm{y}$ a flower] $\mathrm{y}$ is growing in $\mathrm{x}$.

b. \# $[\exists \mathrm{y}$ : $\mathrm{y}$ a flower, $\forall \mathrm{x}$ : $\mathrm{x}$ a pot] $\mathrm{y}$ is growing in $\mathrm{x}$.

(29) ????Olha! Uma flor está a crescer em todos os vasos!

\# [ $\exists \mathrm{y}$ : $\mathrm{y}$ a flower, $\forall \mathrm{x}$ : $\mathrm{x}$ a pot] $\mathrm{y}$ is growing in $\mathrm{x}$.

(27) é potencialmente ambígua entre as leituras representadas em (27a) e (27b). Contudo, apenas (27a) é pragmaticamente adequada, dado que a mesma flor não pode crescer em todos os vasos. (28a), com o sujeito em posição pós-verbal, também é ambígua. (29), porém, só admite a leitura em que o indefinido tem escopo largo; daí o estatuto duvidoso do exemplo 
em português. E aqui é que reside o problema: saber por que razão o $\mathrm{PE}$ difere do inglês neste domínio. ${ }^{5}$

Segundo Barbosa 2000, a resposta a esta pergunta está precisamente no facto de, contrariamente ao que sucede em inglês, o sujeito estar deslocado. (29) é analisada como se segue:

[Uma flor $]_{\mathrm{i}}$ [ está pro $_{i}$ a crescer em todos os vasos]

Recorde-se que a relação estabelecida entre as expressões em DEC e o resto da frase é uma relação de predicação mediada por uma categoria pronominal (pro, no caso em apreço). A expressão deslocada introduz um tópico discursivo acerca do qual o resto da frase é predicado. Por conseguinte, não é de surpreender que um indefinido em DEC tenha uma interpretação específica, o que explica a impossibilidade de obtenção da leitura distribuída em (29). E isto conduz-nos ao segundo problema levantado pela passagem transcrita. Em oposição ao movimento A-barra, que reconstrói, a DEC não reconstrói (veja-se I. Duarte 1987, Cinque 1990) ${ }^{6}$. O seguinte exemplo ilustra isto mesmo:

(31) Alguns livros, não os entreguei a todos os professores.

A frase ilustrada em (31) só pode ser interpretada com escopo largo do indefinido relativamente à negação. Este ponto desempenha um papel fundamental em toda a minha discussão, precisamente por causa da distinção que faço entre deslocação à esquerda e movimento A-barra. Recorde-se que, na teoria que defendo, os sujeitos que desencadeiam a ênclise estão numa posição de deslocação à esquerda; os sujeitos que desencadeiam a próclise movem-se por movimento A-barra. Sendo assim, prevê-se que se verifiquem diferenças entre os dois tipos de sujeitos no que respeita a interacções de escopo com um elementos no interior da frase. E com efeito, esta predição confirma-se, tal como observado em Barbosa (2000). Considere-se o seguinte exemplo:

\footnotetext{
Em nota de rodapé, Costa afirma que estes casos são diferentes dos que ele menciona, o que não é verdade, dado que ilustram exactamente o mesmo fenómeno, nomeadamente relações de escopo. 6 Cinque 1990 apresenta argumentos a favor da não reconstrução da DEC. Há apenas um fenómeno gramatical relativamente ao qual há efeitos de reconstrução: a Condição C da Teoria da Ligação (a este propósito, veja-se Barbosa 1995).
} 
(32) Algo de estranho está a crescer em todos os vasos.

[Todos os vasos $\mathrm{y}$, algo de estranho $\mathrm{x}$ ] $\mathrm{x}$ está a crescer em $\mathrm{y}$

(32), com uma expressão não referencial quantificada desencadeadora de próclise (cf. Algo de estranho se está a passar ali) admite a leitura distributiva, contrariamente a (29). Em (32), o indefinido não está deslocado e é movido para a posição pré-verbal por movimento A-barra (na representação que se segue uso o termo neutro FP para designar a projecção funcional cujo especificador serve de ponto de chegada ao movimento do QP): $\complement_{\mathrm{FP}}[\text { Algo de estranho }]_{\mathrm{i}}$ está a crescer $v_{\mathrm{i}}$ em todos os vasos $]$.

Por hipótese, a leitura com escopo estreito resulta da possibilidade de elevação do quantificador universal para um posição de adjunção à projecção funcional que contém o indefinido.

A interpretação dos sujeitos indefinidos constitui, assim, um argumento em favor da nossa análise e um problema para a análise canónica. Se o sujeito está em Spec-IP tanto em (29) como em (32) não só não se compreende a diferença entre o PE (cf. (29)) e o inglês (cf. (27)) como não se percebe o contraste entre (29) e (32) no que respeita à interpretação do indefinido. $\mathrm{Na}$ análise por nós proposta, estes factos encontram explicação imediata.

Costa afirma o seguinte a propósito do contraste entre (28) e (29):

Parece-me, no entanto, que contrastes como em (i) [os nossos exemplos (28-29)] apenas mostram que havendo duas posições para o sujeito (independentemente do seu estatuto como posição-A ou A-barra), estas podem ser usadas em contextos diferentes (cf. Costa 1998). Por outras palavras, o contraste em (i) $/[(28 / 29)]$ não fornece evidência a favor de qualquer uma das hipóteses relativamente à posição dos sujeitos pré-verbais.

Exemplos como (32), aqui repetido em (34a), são um problema para esta explicação "funcional": neste caso, o escopo estreito é possível, apesar de a configuração com o sujeito pós-verbal também ser uma alternativa (cf. (34)):

(34) a. Algo de estranho está a crescer em todos os vasos.

b. Está a crescer algo de estranho em todos os vasos. 
Finalmente, um palavra acerca do exemplo (8b) da passagem do texto original de Costa citada no início desta secção. Para Costa, (8b) é ambígua, contrariamente a (8a). Em primeiro lugar, devo dizer que discordo do juízo de Costa. Para mim, (8b) só tem uma interpretação: a de que os mesmos três livros foram lidos por dois estudantes (isto é, a leitura com escopo largo do DP em DEC). Mas, independentemente dos juízos que se possam atribuir ao exemplo em questão, há um outro problema de fundo. Com este exemplo, Costa pretende mostrar que o objecto deslocado pode ser interpretado com escopo estreito. Contudo, para o demonstrar, é necessário usar exemplos como (31), em que o objecto deslocado interage com um elemento no interior da frase, e não exemplos em que há interacção com um sujeito, porque o que está em causa é precisamente o estatuto do sujeito. $\mathrm{Na}$ análise da deslocação, ambos os indefinidos estão deslocados, portanto ( $8 \mathrm{~b})$ não tem valor de prova. O exemplo (31), que não envolve sujeitos, é o que deve ser usado para averiguar se os objectos deslocados podem ou não ter escopo estreito relativamente a operadores contidos no interior da frase. Como se vê em (31), não têm (ver também, a este propósito, Duarte 1987, Cinque 1990), e é por isso que a argumento apresentado não colhe.

\subsubsection{Movimento limitado do sujeito}

Costa observa que o movimento do sujeito é limitado, não atravessando mais do que uma oração, e dá os seguintes exemplos (o juízo indicado em (35b) é seu):

a. A Maria foi assassinada.

b. *A Maria (,) foi dito/dita que foi assassinada. [Costa 2001]

O autor acrescenta que o contraste obtido em (35b) não é reproduzido na frase (36), na qual o objecto directo é deslocado à esquerda:

Esse bolo, disseram-me que o comi.

O autor conclui o seguinte “... este tipo de contraste pode ser explicado facilmente assumindo-se que o sujeito pré-verbal se encontra em SpecIP, sendo a natureza do movimento para esta posição diferente do tipo de representação gerada quando há deslocação à esquerda clítica."

O tipo de representação gerada quando há deslocação à esquerda clítica é uma construção de redobro pronominal, portanto, no caso da desloca- 
ção do sujeito, envolve sempre um sujeito pronominal nulo, que é o verdadeiro sujeito argumental. Esse sujeito nulo é que se eleva ou não. Assim, o exemplo (37a) só pode ter a representação indicada em (37b)

(37) a. *A Maria foi dita que foi assassinada.

b. [A Maria $\left[\right.$ [ $\operatorname{pro}_{\mathrm{i}}$ foi dita [que $\left[\mathrm{v}_{\mathrm{i}}\right.$ foi assassinada $]$ ].

(37b) envolve elevação de pro para fora de um domínio finito (Superraising), o que é impossível em PE. (38a), por outro lado, com a forma masculina do particípio, tem a representação em (38b):

(38) a. A Maria, foi dito que foi assassinada.

b. A Maria ${ }_{i}$ [foi dito [que pro ${ }_{i}$ foi assassinada]]

Em (38), o sujeito da frase superior é a oração finita em posição pósverbal (ou, alternativamente, um expletivo nulo, dependendo das análises). Neste caso, o DP 'A Maria' estabelece uma relação com o sujeito nulo da oração subordinada (note-se que esta não é uma relação de movimento, mas de co-referência). Este exemplo exige pausa, porque é preciso esperar pela oração subordinada para encontrar a categoria pronominal com a qual o DP deslocado se relaciona. Porém, é gramatical, tal como o são todos os exemplos que se seguem:

(39) a. Esse bolo, disseram-me que está estragado.

b. Esse bolo, acho que está estragado.

(40) é que eles parece que quase que não pagam contribuições [Português Fundamental (PF), Corpus de Referência do Português Fundamental (CRPF), Centro de Linguística da Universidade de Lisboa (CLUL)]

(39a) é a contrapartida exacta de (38a), com deslocação do sujeito. (39a,b) são exemplos criados por mim, mas (40) é retirado de um corpus de fala. Não há como negar que (40) é exactamente a mesma configuração de (38a), com a diferença de que (38a) contém uma passiva e (40) contém uma construção com parecer. Ora se há deslocação em exemplos como (40), não há como impedir a geração de (38a). Com efeito, Costa menciona os exemplos que se seguem e reconhece que estes são casos de deslocação do sujeito:

(41) a. O homem parece que viu um monstro.

b. O João parece que está parvo. 
De facto, estes exemplos não envolvem elevação, uma vez que, se colocarmos o DP no plural, o verbo não concorda com este:

(42) a. Os homens parece que viram um monstro.

b. As crianças parece que estão parvas.

Para além disso, o DP em posição inicial pode relacionar-se com uma posição a distância:

(43) O homem parece que não há dúvida de que viu um monstro.

Por conseguinte, tanto (41a,b) como (42-43) são inequivocamente analisados como indicado em (44) para o exemplo (42a):

(44) Os homens [parece que pro viram um monstro]

Em (44), o sujeito de 'parecer' é um expletivo (ou, dependendo das análises, a oração subordinada). O DP 'os homens' está deslocado e relaciona-se com o sujeito nulo da oração encaixada. Por conseguinte, (41-43) são casos de deslocação à distância, a configuração que Costa afirma não existir ao negar a gramaticalidade de (38a).

A relevância destes exemplos está nos casos ilustrados em (41a,b). Uma vez que tanto o verbo como o DP deslocado estão no singular, estes exemplos são frequentemente tomados como casos de elevação do sujeito, isto é, é frequente os falantes se convencerem de que, em (41a,b), o sujeito da frase superior é o DP 'o homem’ ou 'o João', quando na realidade não o é. Isto prova, portanto, que é extremamente difícil detectar a deslocação a olho nu sempre que há concordância (ainda que aparente) entre o DP deslocado e a flexão verbal do verbo superior e a relação entre os dois é local. Este ponto é importante, porque, quando os traços de concordância não coincidem, como em (42a,b), ou a relação não é suficientemente local, como em (43), esta questão não se coloca.

Uma vez clarificada este ponto, consideremos a argumentação de Costa. O autor afirma que, se o sujeito pré-verbal for indefinido, esta construção torna-se "mais difícil" e menciona os seguintes exemplos (juízos seus):

(45) a. *Umas meninas parece que estão doentes.

b. *Baleias parece que comem peixe. 
A (45a,b), Costa contrapõe os exemplos em (46) e conclui que estes contrastes constituem um argumento contra a ideia de que os sujeitos estão deslocados em (46a-c).

(46) a. O homem foi assassinado.

a'. Um homem foi assassinado.

b. As meninas estão doentes.

b'. Umas meninas estão doentes.

c. As baleias comem peixe.

c'. Baleias comem peixe.

Antes de mais, devo dizer que não usaria um asterisco em (45a), porque não acho que a frase seja agramatical; uma vez que, em minha opinião, cada uma das frases de (45) ilustra fenómenos diferentes, discuti-las-ei separadamente.

Consideremos, em primeiro lugar, (45b), aqui repetido em (47b), em oposição a (46c'), repetido em (47a):

(47) a. Baleias comem peixe.

b. *Baleias parece que comem peixe.

É sabido que os nomes simples (bare nouns) sem modificação não são bons em posição pré-verbal nas línguas românicas de sujeito nulo (ver Longobardi 2000, entre outros). A única excepção a este padrão são os frases definitórias. Oliveira 2002 menciona os seguintes exemplos:

(48) a. Quadras são estrofes de quatro versos

b. Baleias são mamíferos de grandes dimensões

c. ?? Elefantes estão extintos

d. * Elefantes são inteligentes

e. *Elefantes estão no parque

Em minha opinião, (47a) aproxima-se de um contexto definitório. Em (47b), porém, o que é predicado do nome simples deslocado é a proposição expressa pela fórmula (parece (pro comem peixe)). Dado que o verbo 'parecer' não indica certeza na verdade do seu complemento, não é difícil perceber que esta frase não cumpre os requisitos dos contextos definitórios, que são categóricos. Logo, o nome simples não é admitido em (47b) como não o é nos exemplos (48c-d). 
Regressemos agora à frase (45a). Quando comparamos esta frase com (46a'-b'), verificamos que não há um exacto paralelismo entre estes exemplos na medida em que Costa só usa um exemplo com um indefinido com parecer e esse indefinido está no plural (cf. (45a)). Isto é, falta a equivalente de (46a'). Completemos, então, o paradigma:

(49) a. Um homem foi assassinado.

b. Um homem parece que foi assassinado.

(50) a. Umas crianças estão doentes.

b. Umas crianças parece que estão doentes.

Para mim, (49a,b) não diferem substancialmente. (50a,b), por outro lado, precisam de mais contexto, uma vez que o indefinido no plural exige uma leitura partitiva. Assim descontextualizadas, ambas as frases são algo estranhas. A diferença entre as duas está em que (50b) acrescenta à estranheza de (50a) um custo adicional de processamento provocado pela ausência de coincidência nos traços de concordância do DP deslocado e do verbo superior; por conseguinte, é natural que o resultado seja duplamente estranho, na ausência de um contexto apropriado. Imaginemos agora uma situação em que a Maria, educadora de infância, fala ao telefone em altos berros com uma funcionária da instituição em que trabalha. Eu pergunto ao Pedro, 'O que se passa?, e ele responde:

(51) Umas meninas parece que estão doentes e a funcionária não consegue encontrar um médico de serviço.

Para mim, (51) é perfeita neste contexto, pelo que encerro a questão por aqui.

3.2. DEC de sujeito vs. DEC de objecto

3.2.1. As ordens OSV e SOV

Costa observa que existe um contraste entre as ordens OSV e SOV e menciona os seguintes exemplos, colocando uma estrela no exemplo (52b):

(52) a. Esse bolo, o Paulo comeu-o.

b. *O Paulo, esse bolo comeu-o. [Juízo de Costa 2001] 
Uma vez que, nos casos de deslocação múltipla, a ordem dos elementos não é fixa, a teoria da deslocação prevê que ambas as ordens, OSV e SOV sejam possíveis. Assim, o juízo indicado para (52b) constitui um argumento contra a ideia de que o sujeito está deslocado.

Para mim, (52b) não é agramatical. A corroborar o meu juízo posso citar dados da fala natural que evidenciam a ordem que Costa rejeita. Alguns deles contêm objectos topicalizados (cf. (54a,b); outros, dativos sem redobro pronominal (cf. 53a,b); outros ainda, objectos directos (54c) e indirectos (cf. (54d) com redobro. Todos evidenciam a ordem SOV:

(53) a. ... Por isso não percebo esta birrinha, digna apenas de criancinhas da primária (eu ao meu filho de 8 anos não a admitiria). blogaopost.blogspot.com/

b. E ele ao polícia disse que desconhecia a existência daquela nota, que devia ser do cunhado. Corpus CETEMPúblico, Linguateca, Ext 515884.

(54) a. Eu isso não faço, não sou capaz

[Corpus Português Fundamental (PF) 0951.txt $]^{7}$

b. Os burros não fugiram porque vinha lá o dono com eles! Eu - mas eu essa já não vi! [PF1058.txt]

c. quer dizer, eles a nós estudam-nos, e nós também os estudamos, não é. [PF1023.txt]

$\mathrm{d}$. e isso a mim, levou-me a que eu tivesse curiosidade nos livros [ortot.txt (corpus do DCP (Dicionário de Combinatórias do Português)]

Julgo que qualquer falante do PE reconhece que os exemplos citados fazem parte do uso corrente. Portanto, a menos que Costa queira afirmar que uma grande parte das frases que utilizamos no dia a dia não são geradas pela gramática, terá que concluir que a ordem SOV é possível em PE.

Dar-se-á o caso de Costa se referir ao português escrito quando coloca o asterisco em (52b), de tal forma que o seu juízo mudaria se fosse colocada uma vírgula a seguir ao objecto?

(55) O Paulo, esse bolo, comeu-o.

Suspeitamos que sim. Embora, na fala, nem sempre os objectos topicalizados ou deslocados à esquerda exijam pausa entoacional (cf. 54a-d), reconhecemos que a frase (52b), assim descontextualizada, exige pausa.

Estes exemplos são retirados do Corpus de Referência do Português Contemporâneo (CRPC) do Centro de Linguística da Universidade de Lisboa (CLUL). Agradeço aos membros do Centro a sua disponibilidade para fazer a busca nos corpora. 
Contudo, se é esse o caso, então o conteúdo do contra-argumento muda. Este pode ser reformulado da seguinte forma: os objectos deslocados possuem um curva entoacional com propriedades particulares, (cf. 52a); sendo assim, a análise da deslocação prevê que os sujeitos pré-verbais tenham o mesmo contorno entoacional dos objectos em DEC; contudo, em (52a) o sujeito pré-verbal não tem as mesmas propriedades prosódicas do objecto em (55); esta observação constitui um problema para a teoria de que o sujeito em (52a) está deslocado e um argumento para ideia de que ele ocupa a posição canónica. Abordemos, então, este contra-argumento.

É verdade que os objectos em DEC têm uma curva entoacional particular. Porém, o argumento acima apresentado só colhe se for o caso que as construções com objectos em DEC têm as mesmas propriedades prosódicas das construções com sujeitos em DEC. À priori, não há razões para pensar que sim. Por conseguinte, a questão em apreço só pode ser decidida empiricamente e será abordada nas secções seguintes.

\subsubsection{A DEC de sujeitos e a DE de objectos não têm as mesmas propriedades prosódicas e informacionais}

Considerem-se os seguintes exemplos:
a. O João onde foi?
b. As crianças a que horas se vão deitar?
c. Eles em quem votaram?

Os exemplos transcritos diferem dos de Costa pelo facto de o elemento que segue o sujeito não ser um objecto em DEC, mas sim um constituinte QU. Nestes casos, não há como negar que o sujeito está deslocado, porque não pode, como é evidente, estar em Spec-IP. Por outro lado, exemplos deste tipo só se encontram nas línguas de sujeito nulo, em que o redobro do sujeito por uma sujeito silencioso permite a sua derivação:

$$
\text { O João } L_{\mathrm{CP}} \text { onde foi pro]? }
$$

Estes exemplos são importantes porque revelam que os sujeitos deslocados têm propriedades prosódicas diferentes dos objectos em DEC. Em (56) não é necessária uma pausa entre o sujeito e o resto da frase. As frases soam naturais sem pausa e, presumivelmente, ninguém poria uma vírgula entre o sujeito e o resto da frase neste caso. 
Considerem-se agora exemplos comparáveis com DEC de objecto:

a. Esse bolo, quando o fizeste?

b. As crianças, a que horas as vais deitar?

Na minha opinião, os exemplos transcritos exigem uma mais nítida demarcação prosódica do sintagma em DEC do que os transcritos em (56), de tal forma que, na escrita, se justifica a inserção da vírgula, contrariamente ao que sucede em (56). Por conseguinte, estes dados revelam que há diferenças entre sujeitos e objectos deslocados no que respeita à estrutura prosódica, o que põe em causa os fundamentos do contra-argumento baseado na entoação prosódica.

(56a-c) são particularmente interessantes porque constituem pares mínimos com (55). A única diferença entre (56a-c) e (55) está na natureza do elemento que intervém entre o sujeito deslocado e a flexão verbal: em (56a-c) esse elemento é um constituinte interrogativo, que forma uma unidade prosódica com o resto da frase; em (55) é um objecto em DEC, que (tipicamente) não forma uma unidade prosódica com o resto da frase. Este facto tem consequências para a prosodização do sujeito deslocado: em (56), não é necessária pausa entre o sujeito deslocado e o resto da frase; em (55) a pausa parece necessária, pelo menos quando a frase ocorre assim, descontextualizada. É evidente que estas são as minhas intuições, mas julgo que são partilhadas pela maioria dos falantes. A conclusão a tirar destes factos é que a exigência de pausa na fronteira direita de um sujeito deslocado não depende tanto de propriedades inerentes da configuração de deslocação propriamente dita como da natureza do elemento que intervém entre ele e o resto da frase. Quando o elemento que intervém é um objecto topicalizado ou em DEC a pausa é necessária ou pelo menos previsível; quando o elemento que intervém forma uma unidade prosódica com o resto da frase, a pausa não é necessária nem previsível (cf. (56)). Sendo assim, não é de esperar a ocorrência de uma pausa quando o sujeito deslocado e a flexão verbal estão adjacentes, como sucede em (52a) (na análise de (52a) em termos de deslocação, como óbvio).

Em síntese, o argumento de Costa assenta no pressuposto de que a DEC de sujeitos e a DEC de objectos partilham as mesmas propriedades prosódicas. Todavia, os exemplos examinados nesta secção não parecem corroborar este pressuposto.

Para além da questão prosódica, há também propriedades informacionais que distinguem a DEC de sujeito da DEC de objecto: a DEC de sujei- 
to é intuída como mais neutra do ponto de vista informacional. Há dois tipos de considerações internas ao PE que confirmam esta afirmação. Em primeiro lugar, temos os exemplos em (56a-c), que são intuídos como mais neutros do ponto de vista informacional do que (58a,b). Em segundo lugar, temos os casos de recomplementação (Raposo 1994, Barbosa 2000)). Uma rápida busca nos corpora do CLUL revela que a recomplementação com sujeitos é extremamente frequente na fala. A seguir, transcrevo alguns dos exemplos encontrados no corpus do Português Fundamental (PF) (Corpus de Referência do Português Contemporâneo, CLUL):

(59) a. ele disse que o pai que tinha muitas coisas dessas lá em casa (PF - 0032)

b. acho que uma pessoa que deve desfrutar da vida o melhor que puder (PF 0130)

c. eu julgo que o senhor professor que esteve no seminário (PF 0012)

d. eu acho que ele que não tem é grande queda para estudar (PF 0520)

Em (59a-d) o sujeito está claramente deslocado. Com efeito, estes exemplos só podem ser analisados como deslocação à esquerda, até porque alternam com frases como as que se seguem, em que o elemento que ocorre entre os dois complementadores é uma expressão adverbial de âmbito frásico:

(60) a. dizem que hoje que é a melhor máquina que há aí (PF)

b. nem disseram que lá fora que lhes disseram para não vir (PF)

c. e ele diz que não, que agora que fica cá โortot.txt, corpus do DCP (Dicionário de Combinatórias do Português), CRPC]

É interessante verificar que, de um total de 52 ocorrências de recomplementação, 39 são com sujeitos. Os outros casos são com expressões adverbiais $^{8}$. Esta alta frequência de sujeitos visivelmente deslocados é sugestiva. Note-se ainda que, na maior parte dos casos, o falante não está consciente de que usou a recomplementação. Retire-se o segundo complementador nos exemplos citados, e temos um sujeito pré-verbal tão neutro como qualquer outro. Sendo assim, chegamos à conclusão de que as propriedades informacionais do sujeito em (59) são as mesmas que as de um sujeito correspondente numa estrutura simples SVO; logo, não é possível

8 Este paralelismo entre as expressões adverbiais de âmbito frásico ('frame adverbials') e os sujeitos pré-verbais é bastante curioso, porque se verifica noutras áreas também, a saber, no padrão de colocação do pronome clítico, tal como observado em Barbosa (2000). 
argumentar a partir das propriedades informacionais de um sujeito que ele não possa estar deslocado numa estrutura SVO.

A observação de que a DEC de sujeito tem caraterísticas prosódicas e informacionais diferentes da DEC de objecto é também uma das conclusões do estudo de Baker (2003) sobre as línguas polissintéticas como o Mohawk:

Phonological and/or pragmatic evidence is sometimes used to tell if an NP is dislocated. For example, dislocated NPs are sometimes set off from the rest of the clause by an intonation break, and they are sometimes associated with topic or contrastive focus interpretations (see Rice (this volume) on Slave). The Pronominal Argument Hypothesis is committed to there being cases of syntactic dislocation that do not have these nonsyntactic properties, however. NPs in Mohawk, for example, need not be set off intonationally, and they can have any discourse function. I show below that agreed-with objects in Kinande have these phonological and pragmatic characteristics of dislocation, but agreed-with subjects do not. All this implies that there are natural interconnections between the various components of language, but they are not fully deterministic.

Estas observações estão em conformidade com o que acabámos de dizer para o PE.

Uma vez que muita da argumentação contra a deslocação dos sujeitos assenta na comparação sistemática com os objectos em DEC, e, como acabámos de ver, nem sempre é legítimo fazer extrapolações da DEC de objecto para a DEC de sujeitos, convém tentarmos perceber melhor quais as propriedades da DEC de sujeito. Para tal, teremos de usar dados de línguas em que a DEC de sujeitos seja visível e produtiva. É o caso do francês e do português do Brasil (PB), como veremos.

\subsubsection{As construções de "duplo sujeito" em francês e PB}

Nesta secção examino os dados do estudo de M. E. Duarte (1993, 1995) sobre a emergência, em BP, de construções de redobro do sujeito, como a ilustrada em (61):

(61) a. A Clarinha $a_{\mathrm{i}}$ ela $\mathrm{i}_{\mathrm{i}}$ cozinha que é uma maravilha.

b. Então o Instituto de Física ele $_{\mathrm{i}}$ manda os piores professores...

c. Eu, eu sinto demais isso. 
M. E. Duarte 1995 discute as ocorrências destas construções em amostras de fala espontânea e dos media, e mostra a evolução da construção, que está hoje plenamente incorporada na sintaxe do PB. A autora relaciona o uso produtivo do redobro do sujeito com a tendência para o preenchimento da posição de sujeito em PB nos mesmos contextos em que o PE usa um sujeito nulo e propõe que, graças ao empobrecimento dos traços de concordância, o PB está gradualmente as perder as propriedades associadas ao Parâmetro do Sujeito Nulo.

M. E. Duarte observa que, nas línguas pro-drop, esta construção é muito rara (veja-se Ochs \& Duranti 1979 para o italiano, Rivero 1980 para o castelhano e M. E. Duarte 1987, para o PE), embora seja frequente no francês coloquial. Vale a pena citar aqui as conclusões do estudo de Barnes 1986, baseado num corpus do francês oral, citadas por M. E. Duarte:

- a mais frequente das estruturas com DEC é a que tem como elemento co-referente o sujeito: $81 \%$ das sentenças com DEC;

- a construção não se restringe à motivação pragmática de referir-se sempre a um elemento dado no discurso, podendo introduzir elementos novos, sem qualquer marca contrastiva, e tão pouco carrega marca fonológica especial, podendo ou não ser seguida de pausa e podendo ocorrer em frases encaixadas:

(62) M: Non, non, on est obligé de plonger.

C: On était obligé, le mec il m'a poussée!

(63) J'avais un philosophe, un type dont la matière principale c'est la philosophie.

(64) Moi je fait pas confidence au médecin...

No que respeita ao $\mathrm{PB}, \mathrm{M}$. E. Duarte salienta os seguintes aspectos que sugerem mudanças no estatuto desta construção.

I. em primeiro lugar, não se verificam na amostra restrições relativas ao $\mathrm{SN}$ em redobro como sendo elemento dado e definido; as construções com redobro do sujeito podem envolver SNs indefinidos (cf. 65) ou genéricos (66) ou mesmo orações relativas sem antecedente (67):

(65) Eu acho que [um trabalho $]_{i}$ ele $_{i}$ teria que começar por aí.

(66) $[\mathrm{Um} \text { homem comum }]_{\mathrm{i}}$ ele $_{\mathrm{i}}$ tem um conforto compatível com a dignidade de uma pessoa humana, entendeu?

(67) [Quem vem fazer compras no Serra e Mar $_{i}$ ele $_{i}$ não faz compras, ele ${ }_{i}$ passa momentos de alegria e satisfação. (locutor dentro de um supermercado) 
II. a pausa não é característica da estrutura, parecendo dever-se mais à existência de elementos intervenientes entre o $\mathrm{SN}$ e o pronome;

III. há uma mudança no âmbito de acção da estrutura: o seu aparecimento retomando pronomes de primeira (cf. (61c)) e terceira pessoas e com referência arbitrária e ainda a sua ocorrência em domínios encaixados (cf. $(68 \mathrm{a}, \mathrm{b}))$.

(68) a....é porque existe uma filosofia [que [o ${\text { preço }]_{i}}_{\text {ele }}$ tem uma paridade em torno de ...

b. Então se [esse sistema de proteção $]_{i}$ ele $_{i}$ existe pode ter sido...(TV)

As conclusões de M. E. Duarte confirmam a ideia defendida na secção anterior de que a DEC do sujeito não tem as mesmas propriedades prosódicas e informacionais da DEC de objecto. Muito se tem escrito acerca da presença de pausa na DEC de objecto ou da sua incompatibilidade com indefinidos. Como se vê, nem uma nem outra propriedade se verifica na DEC do sujeito. Em síntese, os dados discutidos nesta secção colocam em causa o valor de prova de qualquer argumento baseado nas propriedades prosódicas e informacionais das construções com DEC do objecto.

\subsubsection{Diferenças posicionais entre os objectos e os sujeitos em DEC}

Vimos até agora que a DEC de sujeito e a DEC de objecto têm propriedades prosódicas e informacionais diferentes. $\mathrm{O}$ carácter mais neutro da DEC de sujeito tem uma explicação: dos dois tipos de construção, apenas a DEC de objecto altera a ordem dos argumentos tal como eles são projectados na base. Como tal, é compreensível que a DEC de objecto seja usada apenas em determinados contextos e com uma dada intencionalidade discursiva (cf. o conceito de tópico marcado de I. Duarte 1987). Contudo, para além das diferenças prosódicas e informacionais, há outras, de carácter distribucional, que ultrapassam esta explicação meramente funcional.

Costa observa que há contextos em que um sujeito pré-verbal é possível e um o objecto em DEC não o é e dá o seguinte exemplo:

(69) a. Perguntei que livro o Pedro leu.

b. *Perguntei que livro, à Maria, lhe deram. 
A este exemplo podem acrescentar-se outros semelhantes (veja-se Duarte 1997), dos quais salientamos as orações relativas (Costa e Duarte 2002) e interrogativas não encaixadas com um constituinte interrogativo com restrição lexical:

(70) a. Já li o livro que o João ofereceu à Maria.

b. * Já li o livro que, à Maria, lhe ofereceu ontem o João.

[Costa \& Duarte 2002)

(71) a. Que livros a funcionária enviou?

b. *A que funcionária, esses livros, vais entregá-los?

Costa 2001 e Costa e Duarte 2002 atribuem os juízos em (69b), (70b) e (71b) a um problema de minimalidade e concluem que o facto de o sujeito pré-verbal não interferir com o movimento do objecto indica que aquele não ocupa uma posição A-barra.

Embora não contestemos os factos, a verdade é que a explicação da agramaticalidade de (69b), (70b) e (71b) não pode ser tão simples como os autores citados fazem crer. Em primeiro lugar, a marginalidade dos exemplos parece dever-se mais à presença de um clítico do que ao efeito de intervenção propriamente dito, facto já mencionado em Duarte 1997. Assim, compare-se (69b) com (72a), (70b) com (72b), (73a) com (73b), (74a) com (74b) e (75a) com (75b):

(72) a. Perguntei que livro, à Maria, eles deram no Natal.

b. Já li o livro que, à Maria, ofereceu ontem o João.

(73) a. Não sei ainda a quem, este livro, vou oferecer.

b. */???Não sei ainda a quem, este livro, vou oferecê-lo. ${ }^{9}$

(74) a. Eis uma criança a quem, o nosso carinho, não podemos recusar.

b. */???Eis uma criança a quem, o nosso carinho, não podemos recusá-lo ${ }^{10}$.

(75) a.? Que manuscrito, a essa editora, estás a pensar enviar?

b. *Que manuscrito, a essa editora, estás a pensar enviar-lhe?

9 Rizzi 1997 cita o seguinte exemplo do Italiano que revela que, nesta língua a DEC de objecto pode ocorrer no interior de interrogativas encaixadas.

(i) ?Mi domando a chi, il premio Nobel, lo potrebbero dare.

10 Note-se que os exemplos (74-75) contêm um sujeito nulo. Em minha opinião, as frases pioram consideravelmente quando inserimos um sujeito pré-verbal:

(i) a. *Não sei ainda a quem, este livro, a comissão vai oferecê-lo.

b. *Eis uma criança a quem, o seu carinho, a Maria não pode recusá-lo.

Este facto constitui um problema para a análise tradicional, dado que, nesta teoria não há qualquer diferença entre uma construção com um sujeito nulo e uma construção com um sujeito pré-verbal. 
Com efeito, a ideia de que a topicalização não induz fortes efeitos de minimalidade é consensual (Lasnik \& Saito 1992). Vejam-se o seguintes exemplos do inglês:

(76) The man to whom liberty, we could never grant.

(77) a.? I wonder to whom this book I should give.

[Baltin (1982)]

b. ? Ask him what book to John he would give.

(Pesetsky 1989)

Apesar de estes exemplos servirem para mostrar que a topicalização não induz fortes efeitos de minimalidade, não são directamente relevantes para a questão dos sujeitos, uma vez é possível demonstrar que os sujeitos não podem ser topicalizados de uma forma geral (cf. Lasnik \& Saito 1992). Por conseguinte, o que verdadeiramente interessa agora é verificar o que sucede com a DEC. Em Barbosa 2000, 2001 verifico que a possibilidade de ocorrência de um elemento em DEC nestes contextos depende da sua localização na hierarquia temática: os EXPERIENCIADORES podem mais naturalmente intervir entre o constituinte QU e a flexão verbal mesmo com um clítico; os ALVos, não. Assim, comparem-se os exemplos que se seguem com (69b, 70b, 75b).

Experienciador

(78) Oração relativa

Vi hoje a casa que, à Maria, mais (lhe) convém comprar.

(79) Interrogativas:

b. Sabes quando, ao Pedro, mais (lhe) convém lá ir?

a. A que horas, ao João, mais (lhe) convém aparecer?

c. Que discos, ao João, mais (lhe) agradará receber?

Belletti \& Rizzi 1991 defendem que, com predicados psicológicos do tipo de 'agradar', o EXPERIENCIADOR é gerado na base numa posição mais alta do que o TEMA e a posição de sujeito é não temática. Sendo assim, o que distingue os exemplos (78-79) de (69b, 70b, 73b, 74b, 75b) é o facto de, no primeiro caso, o tópico se relacionar com o argumento mais alto da oração. Assumindo que o EXPERIENCIADOR ocupa uma posição mais alta do que o ALVO e o TEMA, chegamos à seguinte conclusão:

(80) Quando a expressão em DEC está ligada à posição argumental mais alta da oração, pode intervir (com ou sem clítico) entre um constituinte QU e a flexão verbal em todos os contextos em que um sujeito pode intervir. 
Uma explicação possível para (80) está em considerar que os dativos em causa são sujeitos. Contudo, essa opção parece-nos muito pouco plausível dada a possibilidade de co-ocorrência do oblíquo com um clítico na forma dativa. Por outro lado, estes oblíquos podem manter relações à distância com a posição argumental a que se associam tal como sucede com os elementos deslocados:

(81) a. À Maria, consta que não (lhe) agrada nada a promoção do Pedro.

b. Ao presidente, é óbvio que não (lhe) convém nada que o PSD ganhe as eleições.

Por conseguinte, não nos parece razoável a proposta de que estes oblíquos são sujeitos. Contudo, se estas expressões não são sujeitos, então não é o caso que apenas os sujeitos podem intervir entre um constituinte $Q U$ e a flexão verbal nestes contextos e o argumento de Costa 2001 e Costa e Duarte 2002 perde a sua força.

Esta relação entre 'argumento mais alto' e a possibilidade de ocorrência de um tópico deslocado à direita de um constituinte $Q u$ verifica-se também em francês. Nesta língua, é possível verificar a existência de uma assimetria entre sujeitos e objectos em DEC em contextos semelhantes ${ }^{12}$ :

- Sujeitos versus objectos

(82) a. La personne à qui, Jean, il a parlé ...

b. *La personne à qui, ce livre, Jean l'a vendu ...

(83) a. L'endroit où, Jean, il va vivre est inoubliable.

b. *L'endroit où ce livre, Jean l'a vendu est inoubliable.

(84) Je me demande où Jean, il va vivre.

Estes exemplos vêm confirmar a generalização apresentada em (80) e são suficientes para mostrar que a DEC de sujeito não tem exactamente a mesma distribuição da DEC de objecto. Assim, seja qual for a explicação que se possa encontrar para esta assimetria, a verdade é que pode haver deslocação de argumentos altos no interior de relativas ou interrogativas indirectas. Esta observação basta para estabelecer que a objecção de Costa 2001 e Costa e Duarte 2002 não infirma a análise da deslocação (para uma hipó-

\footnotetext{
12 Agradeço a colaboração de Sílvia Araújo na construção dos exemplos. Os juízos de gramaticalidade são de mais do que um falante nativo do francês.
} 
tese de explicação desta assimetria entre a DEC de argumentos altos e a DEC de argumentos baixos, nestes contextos, consultar Baker 2003 e Barbosa 2005).

\subsection{Outros contra-argumentos}

\subsubsection{Posição do sujeito em condicionais sem complementador:}

Em orações subordinadas condicionais sem complementador, ocorre inversão sujeito-verbo em PE, tal como noutras línguas. Este tipo de inversão é tradicionalmente analisado como um caso de movimento do verbo para C. Conforme ilustrado em (85), neste tipo de frases o sujeito ocorre imediatamente a seguir ao verbo flexionado, não podendo ocorrer em posição inicial de frase:

(85) a. Tivesse o João ido ao Brasil...

b. *O João tivesse ido ao Brasil...

De acordo com Costa, "estando o sujeito em Spec,IP, a ordem de palavras em (85a) é a predita, uma vez que o movimento do verbo de I para C atravessará a posição do sujeito. Se o sujeito estivesse deslocado à esquerda, esperar-se-ia encontrar a ordem de palavras em (85b), uma vez que o sujeito estaria adjungido à esquerda de $\mathrm{CP}$, surgindo assim antes da posição de C, que se encontra ocupada pelo verbo".

A argumentação do autor assenta no pressuposto de que é possível haver adjunção a orações condicionais sem complementador. Contudo, acontece que, de uma forma geral, não é possível a adjunção neste tipos de contextos nem em PE nem em inglês. Por conseguinte, não é de prever que um sujeito possa ocorrer em posição pré-verbal neste caso.

(86) a. Tivesse o João ido ao Brasil no ano passado, nada disto aconteceria.

b. *No ano passado tivesse o João ido ao Brasil, nada disto aconteceria.

(87) a. Tivesse o João visto a Maria a tempo, nada disto aconteceria.

b. *A Maria, tivesse-a o João visto a tempo, nada disto aconteceria.

(88) a. Had John been in Brasil last year ...

b. * Last year had John been in Brasil ... 


\subsubsection{QPs negativos sem acento forte}

Um outro argumento apresentado pelo autor em favor da análise segundo a qual os sujeitos pré-verbais se encontram em Spec,IP é o facto de ser possível encontrar QPs negativos em posição inicial de frase à esquerda de um advérbio, como em (89):

(89) Ninguém provavelmente leu esse livro.

Costa observa que esta ordem de palavras não é possível em italiano e cita Belletti 1990, que afirma que as ordens Suj-Adv-V são casos de deslocação à esquerda do sujeito. Segundo Belletti 1990, dado que palavras negativas não podem ser deslocadas à esquerda, espera-se que estas só possam ocorrer naquela ordem de palavras se forem focalizadas:

(90) NESSUNO/*Nessuno probabilmente ha sbagliato.

Costa conclui o seguinte:

O facto de, em português europeu, não existir um contraste semelhante ao do italiano pode indicar que o sujeito pré-verbal não é necessariamente deslocado à esquerda. Em Costa (1996), analisei a ordem de palavras em (5) [o nosso exemplo (124)] como um argumento a favor da ideia de que o verbo em PE não é movido até ao núcleo funcional mais alto.

Em Barbosa 2001, apresento um estudo detalhado da estrutura da periferia esquerda da frase nas línguas românicas que dá conta desta diferença entre o italiano e o português. Recorde-se que, na análise apresentada na secção 2, os quantificadores negativos que aparecem em posição pré-verbal são movidos por movimento A-barra. Em Barbosa 2001, defendi que, sempre que Spec-TP projecta numa Lingua de Sujeito Nulo (consultar a secção seguinte), é uma posição A-barra. Assim, frases como as seguintes do PE e do Italiano são analisadas com movimento do quantificador para Spec-TP:

(91) a. Nessuno ha sbagliato.

b. Ninguém leu esse livro.

(92) [ Nessuno/ninguém ${ }_{\mathrm{i}} \cdots\left[_{\text {Flex }}\left[_{\text {Flex }} V\right]\left[_{\mathrm{Sv}} \quad \mathrm{v}_{\mathrm{i}}\right]\right\}$ 
A existência de posições mais altas disponíveis para alojar o movimento A-barra depende da estrutura da periferia esquerda de cada língua. É sabido que o Italiano não tem topicalização do tipo do português (cf. (93a)), mas tem movimento de Foco (cf. (93b), (94)), como se ilustra a seguir:

(93) a. * Il tuo libro, ho letto $e c$.

b. IL TUO LIBRO ho letto (, non il suo)

[Rizzi 1997]

(94) Credo che QUESTO, a Gianni, gli dovremmo dire.

Em face de exemplos como (94), Rizzi 1997 propõe que o italiano dispõe de uma projecção de Foco situada entre T e C. Sendo assim, não é de admirar que a presença de um advérbio force a focalização do quantificador em (90): FocP situa-se à esquerda de tópicos e advérbios de frase em Italiano.

Tal como observado em I. Duarte 1987, Raposo 1994 e Barbosa 2001, o PE não tem movimento de Foco com as mesmas características das restantes línguas românicas. Em particular, exemplos como (93a) são bons em PE sem que haja necessidade de focalização contrastiva (com foco exclusivo), como sucede no italiano. Para além disso, a anteposição de objectos não referenciais com advérbios intervenientes não exige focalização contrastiva, como se ilustra a seguir:

(95) a. Alguma coisa provavelmente irás esquecer, se não fizeres a lista das compras.

b. Nada provavelmente lhe vão dizer acerca da sua doença.

$(95 \mathrm{a}, \mathrm{b})$ poderão ser ligeiramente enfáticas, mas não exigem focalização com as propriedades descritas para o italiano (Rizzi 1997) ${ }^{13}$. Por outro lado, não me parece que haja diferenças significativas entre (95a,b) e (96a,b), com sujeitos em lugar de objectos antepostos:

(96) a. Alguma coisa provavelmente será esquecida, se não fizeres a lista das compras.

b. Nada provavelmente vai ser dito acerca da sua doença.

13 Raposo (1994) usa a designação 'movimento enfático' para referir este tipo de movimento. Contudo, não me parece que todas as frases que envolvem este tipo de movimento sejam necessariamente enfáticas. É evidente que a anteposição de um objecto só se faz se se quiser de alguma forma salientar esse elemento, portanto há sempre algo de enfático em frases do tipo de (95a,b). Para além disso, o tipo de quantificador utilizado também é determinante (para uma caracterização dos diversos quantificadores que desencadeiam a próclise, ver Martins 1994). 
Para mim, (95) e (96) têm exactamente o mesmo estatuto. Por conseguinte, não vejo por que razão se espera que o PE tenha o mesmo comportamento do italiano. Em particular, não me parece que haja razões internas ao PE que forcem a focalização do quantificador sempre que este ocupa uma posição A-barra situada acima de TP (cf. (95a,b), que contêm objectos antepostos e são perfeitamente gramaticais sem focalização).

Em Barbosa 2000, 2001, defendi que não há como negar a disponibilidade de duas posições A-barra na periferia esquerda da frase em PE. Os seguintes exemplos ilustram isto mesmo:

(97) a. [Nem ao seu melhor amigo $]_{1}$ a Maria [alguma ajuda $]_{2}$ ofereceu $t_{2} t_{1}$ b. $E_{\mathrm{CP}}[\mathrm{Nem} \text { ao seu melhor amigo }]_{1} \mathrm{~L}_{\mathrm{C}^{\prime}}\left[\mathrm{TP}_{\mathrm{TP}}[\mathrm{a} \mathrm{M} .]_{3} \mathrm{~L}_{\mathrm{TP}}[\text { alguma ajuda }]_{2}\right.$ $\mathfrak{L}_{\mathrm{T}}$ ofereceu $\left.\left.\left.\mathrm{pro}_{3} \mathrm{t}_{2} \mathrm{t}_{1}\right] \mathrm{H}\right] \mathrm{H}\right] \mathrm{H}$

Neste exemplo, o sujeito ocupa uma posição de adjunção à projecção que aloja o movimento A-barra do objecto directo, $\mathrm{TP}(=\mathrm{IP})$, por hipótese, e o QP negativo está em Spec-CP.

Note-se que a ideia de que o QP em (96a,b) está em Spec,TP conduz inevitavelmente à proposta de que o verbo não sobe para a projecção flexional mais alta em $\mathrm{PE}^{14}$. Contudo, esta proposta, para além de complicar consideravelmente a arquitectura da frase em PE, enfrenta problemas, dado que não há qualquer evidência de que o PE seja diferente das restantes línguas românicas relativamente ao movimento do verbo (note-se que, mesmo para Belletti 1990, o sujeito está deslocado sempre que entre ele e o verbo intervém um advérbio de frase). Assim, o verbo normalmente precede o advérbio sempre (na sua interpretação de advérbio de quantificação):

\section{O João beija sempre a Maria.}

A possibilidade de (98) é um dos testes clássicos para o movimento longo do verbo (Pollock 1990, Figueiredo 1996). Por outro lado, os dados da elipse do SV (Matos 1992, Martins 1994) indicam que o verbo sobe bem alto em PE, pelo que não vejo argumentos independentes para a não subi-

\footnotetext{
14 Veja-se e Costa e I. Duarte 2002, Costa 2004; os autores defendem que, nestes casos, o sujeito está em Spec-AgrP e o verbo está em T, o núcleo funcional imediatamente abaixo de Agr
} 
da do verbo para a projecção funcional mais alta a não ser a própria necessidade de colocar o sujeito em Spec,IP em (96) e exemplos semelhantes ${ }^{15}$.

\section{Propriedades informacionais das construções SV e V...S em PE e sua integração no quadro de uma teoria geral das Línguas de Sujeito Nulo de concordância rica}

\subsection{Introdução}

Costa observa que, nos contextos em que toda a frase é focalizada, como em respostas à pergunta $O$ que é que aconteceu?, a ordem emergente é a ordem SVO:
A: O que é que aconteceu?
B: a. O Pedro partiu o braço.
b. \#Partiu o Pedro o braço.
c. \#O braço, o Pedro partiu-o.

O autor conclui o seguinte:

O facto de esta ordem de palavras ser emergente é problemática por duas razões. Por um lado, é possível observar que a deslocação à esquerda não é possível neste contexto (9c), sendo portanto difícil explicar por que motivo poderia o sujeito ser deslocado à esquerda se os outros elementos não o podem; por outro lado, ainda que se admitisse que, em circunstâncias especiais, o sujeito poderia ser deslocado à esquerda, esperar-se-ia que este pudesse ocorrer na sua posição de base, o que não acontece, conforme ilustrado em (9b).

Este contra-argumento decompõe-se em dois. O primeiro baseia-se, mais uma vez, no estabelecimento de um paralelismo entre a DEC de sujeitos e a DEC de objectos; porém, como vimos, as propriedades informacionais da DEC de sujeito são diferentes das da DEC de objecto. O segundo prende-se com a inadequação da ordem VSO no contexto dado. Esta questão será abordada nesta secção, em que introduzo a teoria por mim defendida em detalhe.

\footnotetext{
15 Há casos em que sempre pode preceder o verbo, mantendo a leitura de advérbio de quantificação: (i) A Maria sempre comprou o pão.

Nestes casos, o advérbio ocupa uma posição situada na periferia esquerda da frase (uma posição Abarra); isto é, as diferenças entre (98) e (i) não são devidas a alterações na posição ocupada pelo verbo, mas sim a alterações na posição do advérbio.
} 


\subsection{Propriedades informacionais dos sujeitos pré-verbais em PE}

Tem sido frequentemente observado (Ambar 1992, 1998, Costa 1998, I. Duarte 1987, 1997) que factores discursivos e contextuais condicionam a posição do sujeito em PE. Um exemplo ilustrativo deste tipo de condicionamento é a resposta a uma interrogativa sobre o sujeito como a exemplificada em (100):

(100) Quem comeu a sopa?

(101) a. Comeu o João.

b. ??? O João comeu.

No contexto dado, a ordem SV não é apropriada e a posição preferencial para o sujeito é pós-verbal. Por outro lado, em contextos 'neutros' do ponto de vista informacional, a ordem preferencial é a ordem SVO. O carácter não marcado da ordem SVO tem levado a maior parte dos linguistas (Brito e I. Duarte 1983, Ambar 1992, 1998, Martins 1994, I. Duarte 1987, 1997, Costa 1998, 2000, Costa e I. Duarte 2002) a considerar que os sujeitos pré-verbais ocupam a posição canónica, i.e., a mesma posição que tem sido proposta para línguas como o francês, nomeadamente Spec-IP. Factores de ordem discursiva determinam as ordens SV ou V (...) S . Os mecanismos que determinam as duas ordens variam conforme os autores e têm sido objecto de sucessivas modificações. Centrando-me apenas nas considerações de Costa no artigo em apreço e em outros trabalhos (Costa 1998, Costa $2000^{16}$ ), a ideia fundamental é que há duas posições A para o sujeito em PE: a posição in-situ, dentro de VP e a posição em Spec-IP. A primeira está associada a Foco sobre o sujeito, pelo que este se eleva para Spec-IP apenas quando não é foco (informacional ou contrastivo). Uma vez que, em respostas a interrogativas de sujeito, há foco sobre o sujeito, apenas (101a) constitui uma resposta apropriada a (100). Esta abordagem, contudo, não faz mais do que descrever os factos e continua sem explicar, entre outras coisas, a razão pela qual existem as duas posições para o sujeito em PE e não em inglês ou francês, por exemplo.

$\mathrm{Na}$ teoria de Barbosa 1995, as alternâncias SV, VS (e interpretações a elas associadas) em PE decorrem da propriedade do Sujeito Nulo. Com efeito, no quadro das línguas românicas, o PE não é a única língua em que

$\overline{16}$ Costa e I. Duarte (2003) têm uma proposta ligeiramente diferente (consultar a nota 16). 
a ordem SV não é adequada como resposta a interrogativas com foco sobre o sujeito. Efeitos semelhantes têm sido descritos para as línguas românicas de sujeito nulo, que se caracterizam por admitirem sujeitos pré-verbais e pós-verbais. Nestas línguas, a ordem $\mathrm{SV}(\mathrm{O})$ está geralmente associada a juízos categóricos e as construções com sujeitos pós-verbais configuram juízos téticos (veja-se, para o italiano, Calabrese 1991, Saccon 1993, Pinto 1994, Grimshaw \& Samek-Lodovici 1995; para o espanhol, Contreras 1991, Zubizarreta 1998; para o catalão, Vallduví 1990, Sola 1992; e, para o romeno, Dobrovie-Sorin 1994).

As alternâncias SV, V (...) S fazem parte do feixe de propriedades identificadas nos anos oitenta como estando associadas à Propriedade do Sujeito Nulo (Rizzi 1982 , Jaeggli 1984, Burzio 1986 e Jaeggli e Safir 1989). Estas estão sintetizadas em (102):

(102) Feixe de propriedades associadas à propriedade do Sujeito Nulo:

I. sujeitos sem matriz fonológica;

II. a possibilidade de o sujeito ocorrer em posição pós-verbal ("inversão livre"); III. ausência de efeitos qu-vestígio: a extracção do sujeito é necessariamente da posição pós-verbal Rizzi (1982, Jaeggli 1984, Burzio 1986, Campos 1997).

A ausência de efeitos $q u$-vestígio nas línguas românicas de Sujeito Nulo foi atribuída por Rizzi 1982 ao facto de a extracção do sujeito proceder directamente a partir da posição pós-verbal e não da posição pré-verbal. Com efeito, Jaeggli 1984, Burzio 1986 e, mais recentemente, Campos 1997, mostraram que a extracção do sujeito a partir da posição pós-verbal não é uma mera possibilidade, mas sim obrigatória. Esta descoberta levanta a questão de qual a correlação existente entre esta propriedade e a propriedade do sujeito nulo.

Para Rizzi 1982, a Concordância nas LSN pode ser positiva ou negativamente especificada relativamente ao traço [ + Nominal]. Quando a Conc é [-N], a estrutura é semelhante à das línguas sem sujeito nulo, com o sujeito pré-verbal a ocupar a posição canónica. Quando a Conc é nominal, ela permite identificar uma categoria vazia pronominal em posição argumental, pro. Pro pode ser [ \pm referencial]. Se pro é [ + ref], a estrutura resultante é uma frase de sujeito sem matriz fonológica. Quando pro é [-ref], estabelece-se uma relação de CADEIA entre este, a concordância e um sujeito lexical pós-verbal (o sujeito argumental). 
Adaptando a análise de Rizzi 1982 a um quadro teórico mais recente, em que se assume que o sujeito pós-verbal é gerado na base numa posição à direita de $\mathrm{T}$ (no domínio do $\mathrm{vP}$ ou $\mathrm{VP}$ ), poderemos afirmar que, de acordo com esta linha de análise, o movimento do sujeito para [Spec,IP] depende da especificação dos traços da Conc. Se esta é $[+N]$, o sujeito lexical não se move para [Spec,IP]. Se é [-N], o movimento do sujeito lexical é obrigatório. Qualquer defensor do movimento do sujeito para Spec-IP é forçado a adoptar esta postura ${ }^{17}$. Todavia, ela é suspeita, devido à disjunção que contém. Para além disso, esta análise associa as propriedades (i) e (ii) das LSN, mas não permite facilmente acomodar a propriedade (iii), visto deixar em aberto a questão de se saber por que razão a extracção do sujeito não pode ter nunca como ponto de partida a posição de [Spec-IP], contrariamente ao que acontece nas Ls sem sujeito nulo.

Uma variedade de estudos (Rigau 1987, Vallduví1990, 1992, Solà 1992, Barbosa 1994, 1995, 1996a,b, 2000, Alexiadou \& Anagnostopoulou 1998, Pollock 1997, Kato 1999) tem vindo a argumentar que as construções SV(O) nas LSN diferem das construções $\mathrm{SV}(\mathrm{O})$ nas línguas sem sujeito nulo não apenas do ponto de vista informacional, mas também de um ponto de vista estritamente estrutural. Para estes autores, a verdadeira posição temática do sujeito nas LSN é a posição pós-verbal. As construções SV(O) nestas línguas não envolvem nunca movimento-A do sujeito para [Spec,IP] e são antes o resultado da aplicação de mecanismos independentemente atestados de anteposição de argumentos, tais como a Deslocação à Esquerda (DE) do sujeito ou o movimento A-barra.

Em Barbosa 1995, 1996a,b, 2000, apresentei argumentos de vária ordem a favor desta análise. Em particular, defendi a ideia de que em (101a) o DP o João é o sujeito temático e que em (101b) não o é. A derivação de (101a) envolve elevação do verbo para I e o sujeito permanece na posição de base na sintaxe visível (Ordónez 1998 e Costa 1998, entre muitos outros, argumentam a favor da ideia de que o sujeito pós-verbal permanece na posição em que é gerado na base tanto na ordem VOS como na ordem VSO):

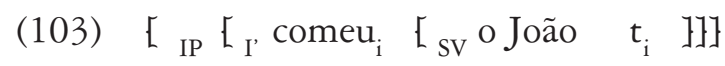

17 Esta é a proposta adoptada em Costa e I. Duarte 2002. Os autores afirmam ainda que só há movimento de V para I em PE quando a Conc é $[+\mathrm{N}]$. Ver a secção 3.4 .2 para uma avaliação crítica da proposta de que o verbo em PE não sobe para I. 
(101b) deverá ser analisada tal como se ilustra a seguir. Em (104) o $\mathrm{DP}$ o João está numa posição de Deslocação à Esquerda (DEC), i.e., é gerado na base numa posição de adjunção a IP (ou CP) e é redobrado por pro, o verdadeiro sujeito argumental ${ }^{18}$ :

(104) $\left[_{\mathrm{IP}} \mathrm{O} \mathrm{João}_{\mathrm{i}}\left[\mathrm{IP}_{\mathrm{IP}}\right.\right.$ comeu $\left.\left.\left[\mathrm{VP}_{\mathrm{VP}} \operatorname{pro}_{\mathrm{i}} \ldots\right]\right]\right]$

Em (104), o DP o João é legitimado por "regras de predicação" na acepção de Chomsky 1977 (cf. também Raposo 1996). IP contém uma posição "aberta" (pro, uma categoria pronominal sem referência independente) satisfeita pela entidade referida pelo DP em DEC. Em (104) o DP em DEC está numa posição de adjunção a IP, mas também pode estar numa posição de adjunção a CP em certos contextos.

Para além da estrutura exemplificada em (104), a ordem SVO pode também ser derivada por movimento A-barra do sujeito directamente a partir da posição pós-verbal, tal como se ilustra a seguir:

(105) $\left[\begin{array}{llll}\text { Sujeito }_{\mathrm{i}} & \ldots & \mathrm{E}_{\mathrm{I}} \mathrm{L}_{\mathrm{I}} \mathrm{V} \quad t_{\mathrm{i}} \ldots\end{array}\right]$

Em Barbosa 1995, 1996a,b, 2000, argumentei que as expressões quantificadas que não podem estar deslocadas tais como quantificadores nús, quantificadores indefinidos não específicos e operadores afectivos (no sentido de Klima 1964) são extraídas por movimento A-barra sempre que precedem o verbo (cf. também Martins 1994, Raposo 1994). Assim, o exemplo do português que se segue será analisado como em $(106)^{19}$ :

(106) Alguém telefonou.

\footnotetext{
18 Sempre que falamos em DE numa língua como o PE estamos tecnicamente a referir-nos à construção com as propriedades da Deslocação à Esquerda Clítica (DEC) descrita por Cinque 1990. $19 \mathrm{Na}$ maior parte das línguas românicas de sujeito nulo (excluindo o português), os DPs definidos também podem ser extraídos por movimento A-barra, o que resulta na construção conhecida na literatura pelo nome de Movimento de Foco, que se exemplifica a seguir:

(i) GIANNI telefona (non Carlo)

Em (i) o sujeito recebe acento contrastivo e evidencia propriedades de reconstrução típicas do movimento A-barra, tal como demonstrado por Cinque 1990 (consultar Torrego 1984 para a descrição de construções deste tipo em castelhano, Bonet 1990, Vallduví 1992 e Sola 1992 para o Catalão, Dobrovie-Sorin 1994 para o Romeno e Cinque 1990, Rizzi 1997 para o Italiano). Para as diferenças entre esta construção e a Topicalização em Português, ver I. Duarte 1987, Uriagereka 1995, Raposo 1996 e Barbosa 2001.
} 
Barbosa 1995 explica a não elevação do sujeito para [Spec,IP] nas LSN mediante eliminação da disjunção contida na proposta original de Rizzi 1982. Para Rizzi, a Conc nas LSN pode ser $[+\mathrm{N}]$ ou $[-\mathrm{N}]$. Eliminando a disjunção, a Conc nas LSN é invariavelmente $[+N]$. Sendo $[+N]$, é capaz de verificar o traço D/N de $\mathrm{T}$ (ou, por outras palavras, o Extended Projection Principle (EPP)). Por esta razão, o sujeito lexical não é atraído para Spec,IP na sintaxe visível. Em Barbosa $(2000,2001)$ propus ainda que a não atracção do sujeito para [Spec,IP] permite que esta posição esteja disponível para alojar constituintes elevados por movimento A-barra, como defendido por Contreras 1991, Bonet 1990, Vallduví 1990, 1992 e Solà 1992.

Embora esta análise possa parecer contra-intuitiva (a ordem mais neutra do ponto de vista informacional é a ordem SV(X)) tem a vantagem de explicar de uma só vez o feixe de propriedades acima descrito:

a) as alternâncias SV/V...S decorrem naturalmente da aplicação de mecanismos independentemente atestados de anteposição de argumentos, a DE e o movimento A-barra;

b) o facto de a extracção do sujeito proceder a partir da posição pósverbal também segue automaticamente: uma vez que esta posição é a verdadeira posição A dos sujeitos, espera-se que seja esta a posição de base para a extracção, em oposição ao que acontece em francês, por exemplo.

Uma outra propriedade que decorre naturalmente da análise proposta é a já referida interpretação de tópico ou tema da maior parte dos sujeitos pré-verbais. Reconsideremos o par pergunta resposta em (100-101). Dissemos que (101a), com o sujeito em posição pós-verbal, é a resposta mais apropriada no contexto dado. Contudo, tal como referido em Âmbar 1998, (101b) é também possível, só que a sua interpretação é diferente da de (101a). (101b) seria apropriada com a continuação indicada em (107), sinónima de 'No que diz respeito ao João, sei que a comeu, mas não sei quem mais o fez'.

(107) A. Quem comeu a sopa?

B. O João comeu ... (mas não sei quem mais o fez).

Ora esta é precisamente a interpretação associada aos tópicos em DEC, no contexto dado. Com efeito, há um exacto paralelismo entre (107B) e (108B), em que o foco da interrogativa é o objecto e a resposta contém um objecto deslocado: 
(108) A. O que comeu o João?

B. A sopa comeu-a ... (mas não sei se comeu o resto).

A resposta com o objecto em DEC tem exactamente a mesma interpretação da resposta em (107B): 'No que respeita à sopa, sei que a comeu, mas não sei se comeu o resto.' Este facto corrobora a análise por mim defendida e constitui um problema para a teoria tradicional, dado que esta não prevê de forma nenhuma qualquer tipo de paralelismo entre o sujeito pré-verbal e um tópico em DEC. Com efeito, como vimos, um dos principais argumentos esgrimidos contra a nossa análise é precisamente a ausência de paralelismo entre a DEC de objecto e as construções com sujeitos pré-verbais. Pois bem, aqui está um exemplo em que esse paralelismo é nítido.

Note-se ainda que, embora esta análise preveja a interpretação temática da maior parte dos sujeitos pré-verbais, não exclui a possibilidade de estes não serem tópicos, como acontece em (106). Neste caso, há extracção A-barra do sujeito.

\subsection{Outras predicõoes}

Para além de explicar de forma imediata o feixe de propriedades indicado em (102), a teoria apresentada explica ainda uma série de outros fenómenos que permanecem misteriosos na abordagem tradicional. Em particular, esta teoria prevê que se verifiquem dois tipos de assimetrias:

a) Diferenças entre as LSN e as línguas sem SN, como o francês e o inglês, no que respeita às propriedades estruturais dos sujeitos pré-verbais;

b) Diferenças entre "sujeitos" específicos e "sujeitos" não referenciais quantificados, no interior das LSN. Este segundo tipo de assimetria prende-se com as propriedades da DEC. Vimos acima que a proposta é que as expressões não referenciais que não podem ser deslocadas são antepostas por movimento A-barra. Sendo assim, prevê-se que, contrariamente ao que sucede em inglês ou francês, as construções SVO em LSN não sejam homogéneas e manifestem propriedades diferentes consoante a expressão nominal utilizada, referencial ou não referencial. 
Em trabalhos anteriores, mostrei que estes dois tipos de assimetria existem e se manifestam numa variedade de fenómenos. As diferenças entre as LSN e as línguas sem SN, verificam-se nos seguintes domínios:

- na distribuição de 'en-avant' com sujeitos pré-verbais em catalão e italiano vs. francês (Barbosa 1995, 1996c, 2000);

- nas restrições à interpretação de pronomes como variáveis ligadas (Barbosa 1995, 1996c);

- nas interacções de escopo entre sujeitos e quantificadores no interior da frase (Barbosa 1995, 2000, 2002);

- na extraposição de orações relativas (Barbosa 1994, Barbosa, Duarte e Kato (no prelo));

- nas diferentes posições do sujeito em construções absolutas (em particular, o facto de o fenómeno conhecido por 'Aux-to-Comp' se verificar apenas em LSN), (Barbosa (2002, Barbosa, Duarte e Kato (no prelo)).

- na distribuição e interpretação dos nomes simples (Longobardi 2000).

As assimetrias entre "sujeitos" específicos e "sujeitos" não referenciais quantificados em PE verificam-se:

- nas restrições à interpretação de pronomes como variáveis ligadas (Barbosa 1995, 1996b);

- nas interacções de escopo entre sujeitos e quantificadores no interior da frase (Barbosa 1995, 2000, Barbosa, Duarte e Kato 2002, no prelo);

- na extraposição de orações relativas (Barbosa 1994, Barbosa, Duarte e Kato (no prelo));

- em infinitivos flexionados em posição de complemento de verbos epistémicos em PE (Barbosa 2000);

- na distribuição da ênclise e próclise com sujeitos pré-verbais em PE (Barbosa 1993, 1996a, 2000).

Como se vê, o domínio empírico abrangido pela teoria proposta é considerável, facto que, em nossa opinião, é subavaliado por Costa no seu levantamento das vantagens da nossa análise. Curiosamente, os defensores da teoria tradicional são omissos acerca da maior parte destes factos. Infelizmente, por razões de espaço, não me é possível apresentar todos esses dados aqui e remetemos o leitor interessado para as obras citadas. 


\subsection{A interpretação "marcada" dos sujeitos pós-verbais}

Um facto que a nossa análise, à partida, não prevê é a interpretação associada aos sujeitos pós-verbais. Como vimos, estes são geralmente interpretados como Foco (informacional ou contrastivo), enquanto os sujeitos pré-verbais são os mais neutros do ponto de vista informacional. Por conseguinte, coloca-se a questão de saber por que razão a posição que, segundo nós, é a verdadeira posição temática (ou argumental) dos sujeitos é a que é mais marcada do ponto de vista informacional. Em resposta a esta pergunta, diremos que este facto resulta de os sujeitos argumentais estarem dentro do VP, sendo assim forçosamente interpretados como fazendo parte do rema, ou do escopo nuclear (há várias teorias deste fenómeno, entre outras a de Diesing 1992, Reinhardt 1995, Zubizarreta 1998, ou, para o PE, Costa 1998).

(109) $\complement_{I P} V_{i}\left[{ }_{V P} t_{i}\right.$ sujeito lexical $]=>\quad$ REMA

Assumindo que os sujeitos in situ fazem invariavelmente parte do rema, a única forma de desfocalizar o sujeito é usar uma representação com DEC, visto que esta permite reestabelecer uma relação de predicação sobre o sujeito; daí que as construções SVO sejam intuídas como mais neutras do ponto de vista informacional do que as construções $\mathrm{V}$...S.

(110) $\left[\left[\mathrm{DP}_{\mathrm{i}}\right] \quad \mathrm{L}_{\mathrm{IP}} \mathrm{V}\left[\right.\right.$ pro $\left.\left._{\mathrm{i}} \mathrm{t}\right]\right]$ Predicação

A ideia de que a interpretação dos sujeitos pós-verbais depende da estrutura Tema-Rema é confirmada pelos exemplos que se seguem. (111) e (112) contêm exemplos com a ordem VSO e o que os distingue é a estrutura Tema/Rema: em (111a,b) não há Tema e toda a frase é Rema; em $(112 \mathrm{a}, \mathrm{b})$ os sintagmas preposicionais em itálico constituem o Tema e a sequencia $\mathrm{VSO}(\mathrm{X})$ é o Rema. Assim pronunciada sem contexto prévio, (111a) só é aceitável com a interpretação de foco contrastivo sobre o sujeito, sendo sinónima de 'Fui eu que perdi o autocarro'; (111b) é bastante estranha. Curiosamente, em (112) estes efeitos desaparecem: (112b) é perfeita e (112a) não exige foco contrastivo sobre o sujeito.

(111) a. Perdi eu o autocarro. [ = Fui eu que perdi o autocarro $]$ b. ???Atirou a Maria um balde de água pela janela. 
(112) a. Vê lá. Por causa das pressas, perdi eu o autocarro.

b. No preciso momento em que eu passava, atirava a Maria um balde de água pela janela.

As diferenças entre (111) e (112) devem-se à estrutura informacional e não à sintaxe e são reveladoras da importância da estrutura Tema-Rema na legitimação de frases com sujeitos pós-verbais. Uma vez que estes, em PE, estão sempre integrados no REMA, a sua ocorrência não é livre e está sujeita às condições de boa formação da estrutura informacional. Em particular, a sua ocorrência é severamente restringida em frases com o verbo em primeira posição, que são invariavelmente remáticas. Nesta perspectiva, não é de surpreender que os contextos preferenciais para este tipo de frases sejam os contextos presentacionais. Considerem-se os seguintes exemplos:

(113) a. Chegou a tua mãe.

b. Telefonou a tua mãe.

c. \#Tossiu a tua mãe. (exemplo adaptado de Costa (2003))

(113a,b) são perfeitas quando enunciadas sem contexto prévio (out of the blue); (103c), porém é inadequada. O paradigma transcrito revela que a adequação da ordem \#VS no contexto dado não depende das propriedades sintácticas do predicado, como por exemplo a inacusatividade (o verbo telefonar é o protótipo de um verbo inergativo e porém tem aqui um comportamento semelhante a um verbo inacusativo, como chegar), mas sim do conteúdo informacional que este veicula: telefonar é 'presentacional' no sentido em que pode ser usado para introduzir um entidade no universo do discurso (cf. a noção de presentational $S$ de Guéron 1980); tossir, por outro lado, não é adequado como verbo 'presentacional' dado que descreve antes uma propriedade de um sujeito temático. É evidente que estas observações aguardam um estudo mais detalhado das complexas relações entre conteúdo lexical e estrutura informacional. Porém, são suficientes para estabelecer que o estatuto mais ou menos marcado da ordem \#VS está mais dependente da estrutura Tema/Rema do que de factores puramente sintácticos.

Em síntese, a hipótese de que a verdadeira posição argumental dos sujeitos em PE é a posição pós-verbal não implica necessariamente que esta posição seja a mais neutra do ponto de vista informacional, dado que não há uma relação biunívoca entre posição argumental e interpretação neutra do ponto de vista informacional. Posto isto, estamos agora em condi- 
ções de reavaliar o contra-argumento de Costa apresentado na introdução a esta secção. Os exemplos relevantes são os seguintes:

(114) A: O que é que aconteceu?

B: a. O Pedro partiu o braço.

b. \# Partiu o Pedro o braço.

c. \#O braço, o Pedro partiu-o.

(114b) não é uma resposta adequada à pergunta A. Acima vimos que, em frases VSO sem rema, como (114b), os sujeito definidos tendem a receber foco contrastivo, pelo que (114b) não é, de forma nenhuma um resposta adequada à pergunta em questão. Por conseguinte, a única forma de desfocalizar o sujeito, neste caso, é construir uma representação em que é restabelecida uma predicação sobre o sujeito, i.e., uma construção de DEC, na nossa análise. Esta construção é a mais neutra do ponto de vista informacional, dado que mantém a ordenação dos constituintes tal como eles são introduzidos na base. (114c) altera as relações de predicação relativamente à estrutura de base na medida em que é uma asserção acerca do braço do João. Por conseguinte, não é informacionalmente adequada enquanto resposta à pergunta em apreço.

Costa observa que o Grego e algumas variedades do espanhol admitem a ordem VSO em resposta à pergunta $O$ que aconteceu? e conclui que este padrão é o predito se a análise da deslocação do sujeito se aplica a estas línguas e não ao PE. Contudo, um facto não mencionado por Costa é que, nestas línguas, a ordem SVO também é admitida nos mesmos contextos, i.e., ambas as ordens são possíveis quando toda a frase é focalizada (veja-se Zubizarreta 1997). Por conseguinte, se tomarmos a possibilidade da ordem VSO em contextos de foco largo como um argumento em favor da análise da deslocação, como faz Costa, teremos de aceitar que a deslocação do sujeito é possível nos mesmos contextos. Isto é o mesmo que admitir que o sujeito pode estar deslocado no exemplo do Português (114a). Desta forma, a objecção de Costa resume-se à pergunta: Por que razão é que algumas LSN admitem a ordem VSO em contextos em que toda a frase está focalizada e outras línguas não? Esta pergunta coloca uma questão interessante, mas não infirma a nossa teoria. Em princípio, há várias formas de abordar o problema. Uma possibilidade de resposta é relacionar esta propriedade do Grego e de certos dialectos do espanhol com o facto de estas línguas terem Clitic Doubling. Outra hipótese ainda é atribuir estas diferenças à forma como se faz o mapping entre a sintaxe e a estrutura informacio- 
nal em cada língua. Como é evidente, este problema constitui por si só um projecto de investigação, mas não é um contra-argumento para a análise da deslocação. O que constituiria um verdadeiro contra-argumento seria a ordem SVO não ser possível em contextos de foco largo nas línguas que admitem a ordem VSO nos mesmos contextos. Porém, ela é possível, o que retira valor de prova à objecção de Costa.

Tendo estabelecido as linhas fundamentais da análise por mim defendida das alternâncias SV/V...S em PE, passo a examinar os restantes contra-argumentos de Costa 2001.

\section{Padrões de concordância}

Costa afirma o seguinte (itálico nosso):

Quando existe inversão sujeito-verbo em contextos inacusativos, a concordância verbal é opcional no português europeu coloquial (Costa 1999), conforme ilustrado em (16):

(16) a. Chegaram três pessoas.

b. Chegou três pessoas.

Quando o sujeito é pré-verbal, a concordância é obrigatória:

(17) a. Três pessoas chegaram.

b. *Três pessoas chegou.

(...) Se o sujeito pré-verbal fosse deslocado à esquerda, o padrão de concordância deveria ser o mesmo em ambas as posiçỗes, dado que não é possivel assumir que a construşão de deslocaşão à esquerda clítica implica mudanças no padrão de concordância verbal.

A afirmação em itálico é surpreendente atendendo à ampla discussão, em Barbosa 1995, 1996b, dos padrões de concordância dos dialectos do Norte de Itália, Trentino e Fiorentino. Essa discussão deixa bem claro que é possível assumir que a construção de deslocação implica mudanças no padrão da concordância.

A construção de deslocação à esquerda envolve sempre um sujeito nulo referencial ou argumental, seja ele pro ou, em algumas teorias, o próprio 
afixo de concordância. Portanto, quando o sujeito é nulo, é fundamental, para a sua identificação, um conjunto suficientemente rico de traços phi (note-se que é precisamente a concordância rica que permite a realização de um sujeito nulo neste tipo de línguas).

Consideremos as representações sintácticas atribuídas a (17a) e (16a) (na numeração do passagem citada) na análise da deslocação:

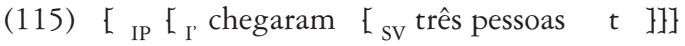

(116) $\left[_{\mathrm{IP}}\right.$ três pessoas ${ }_{\mathrm{i}}\left[\mathrm{IP}_{\mathrm{IP}}\right.$ chegaram pro $\left.\left._{\mathrm{i}} \ldots\right]\right]$

Em (116), o verdadeiro sujeito argumental é pro (ou, em teorias que dispensam pro, como a de Kato 1999, é um vestígio do próprio afixo de concordância); portanto, a concordância tem de ser plena, seja porque é necessária à identificação de pro, seja porque ela própria é um argumento. Em contrapartida, em (115), a concordância não é sequer interpretável, dado que o argumento in situ tem todos os traços phi. Neste caso, [Agr] contém o traço N/D que verifica o EPP, mas os traços phi não são interpretáveis e são apenas o reflexo da concordância com o sujeito in situ. Daí que se compreenda que o traço [número] possa ser omitido no dialecto referido por Costa sem prejuízo dos requisitos de convergência da derivação. Devo afirmar, contudo, que (16) (na numeração original da passagem citada) é para mim inaceitável, e que, a ser possível em certos dialectos, não é nada produtiva em $\mathrm{PE}$ mesmo em registos coloquiais, sobretudo quando comparamos o PE com o PB em que frases como (16), isso sim, são bastante comuns (Kato 1999)..

Convém salientar que a teoria da deslocação não exige que haja concordância em traços phi entre o sujeito deslocado e o sujeito nulo. Uma vez que a relação estabelecida entre estes dois elementos é de co-referência, basta que haja concordância semântica. Com efeito, há casos assim. Em português coloquial, o DP 'a gente', cujos traços gramaticais são [Fem], [Sing] (cf. (117a), pode co-ocorrer com a concordância de primeira pessoa do plural (117b) (Costa e Pereira 2005):

(117) a. A gente está com fome

b. ??A gente estamos com fome. [Português coloquial]

Este fenómeno é facilmente explicado na teoria da deslocação, se a relação que se estabelece entre o DP 'a gente' e o sujeito nulo é uma relação semântica de co-referência. Este tipo de explicação prevê, contudo, que, 
sempre que o DP ‘a gente’ ocorre em posição pós-verbal, seja incompatível com a concordância de primeira pessoa do plural. Isto deve-se ao facto de, neste caso, a teoria assumir que há verdadeira concordância com o sujeito pós-verbal e não co-referência. Com efeito, esta predição confirma-se (pelo menos de acordo com as minhas intuições):

(118) a. Amanhã vai a gente falar com ela.

b. *Amanhã, vamos a gente falar com ela.

Note-se que a impossibilidade de (118b) não entra em contradição com o que dissemos acima acerca de possibilidade de ausência de concordância em número com o sujeito pós-verbal no dialecto que aceita (16b) (na numeração do texto original de Costa). Em (118b) não há apenas ausência de concordância em número mas há também um conflito nos traços de [pessoa] do DP ( $3^{\text {a }}$ pessoa) e de Agr ( $1^{\text {a }}$ pessoa). Portanto, este caso é diferente. Um fenómeno semelhante ocorre em línguas com sujeitos clíticos como os dialectos da Itália do Norte. Nestes dialectos, a ausência de concordância em número com sujeitos pós-verbais não pronominais é frequente. Porém, quando o sujeito pós-verbal é um pronome de primeira ou segunda pessoa, a concordância é obrigatória (Poletto 1992, Barbosa 1995).

Estes factos podem encontrar uma explicação na teoria da concordância baseada no mecanismo AGREE de Chomsky 2004, segundo a qual a relação AGREE exige a não distinção de traços. Em (118b) os traços [pessoa] da concordância verbal e do sujeito pós-verbal são distintos, portanto AGREE falha e os traços phi da flexão verbal não são validados. Por outro lado, se assumirmos que, nos dialectos que aceitam (16b) (da passagem citada) e exemplos semelhantes, o traço de número da terceira pessoa da concordância verbal não está especificado, há não distinção de traços entre a flexão verbal e o DP em posição pós-verbal e a relação AGREE pode estabelecer-se.

Convém salientar que a teoria canónica não tem explicação imediata para estes dados, dado que não prevê que se verifique uma assimetria entre as duas posições - em ambos os casos há uma relação de concordância entre o sujeito e a flexão verbal. Por conseguinte, necessita de estabelecer assunções adicionais acerca da relação de concordância para lidar com estes casos. (cf. Costa e Pereira 2005). 


\section{Redobro por pronome lexicalmente realizado em PE}

Nesta secção examinamos o último dos contra-argumentos de Costa 2001, que se prende com as construções de redobro do sujeito por um pronome lexicalmente realizado. Porém, antes de nos determos na argumentação apresentada pelo autor, vejamos quais são as predições feitas pela análise apresentada na secção anterior relativamente a este tipo de construções.

M. E. Duarte 1995 menciona uma série de estudos que salientam que as construções com duplo sujeito são raras nas LSN. Na nossa perspectiva, esse facto tem uma explicação simples. A única forma de derivar uma construção de duplo sujeito (com o redobro pronominal em posição pré-verbal) numa língua de sujeito nulo é mediante deslocação múltipla, em que os dois DPs deslocados têm o mesmo referente ${ }^{20}$. Assim (119a) terá representação em (119b), nesta análise:

(119) a. O João, ele está doente.

b. O João ${ }_{i}$ [ ele $_{\mathrm{i}}$ [ está pro ${ }_{i}$ doente] $]$

Repare-se que a teoria não prevê que a estrutura em (119b) seja agramatical, uma vez que, em princípio, nada impede a deslocação múltipla, como aliás é reconhecido por Costa. Prevê-se muito simplesmente que seja redundante. Com efeito, frases deste tipo são raras e, sempre que ocorrem, exigem uma pausa bastante acentuada entre o DP e o pronome. Tanto é assim que, na sua discussão das vantagens da análise da deslocação, Costa usa reticências e não vírgula em exemplos semelhantes:

(120) O Pedro...ele foi atropelado. = Ex. (26c de Costa]

Por conseguinte (119a/120) têm características muito diferentes das construções de duplo sujeito do PB descritas por M. E. Duarte 1995. Isto é predito na nossa teoria, uma vez que as estruturas são diferentes: recordese que, em PB, o pronome ocupa a posição de Spec-IP, sendo a contrapartida do nosso nulo. A teoria defendida por Costa não tem este resultado,

20 Um outro contexto em que se prevê que este tipo de deslocação possa ocorrer é em casos de deslocação a longa distância, como no exemplo que a seguir se transcreve:

(i) essa crise mundial admito que ela tenha raiz exactamente numa oferta insuficiente.

[ortot.txt, DCP, CRPC] 
dado que, sem mais modificações, prevê que (119a, 120) tenham a mesma estrutura das construções de duplo sujeito em $\mathrm{PB}$, com o pronome em Spec-IP. Por conseguinte, prevê que o redobro por um pronome possa ocorrer em domínios encaixados, com indefinidos e sem pausa obrigatória. Como explica então Costa que frases como (121), com o duplo sujeito num domínio encaixado, não ocorram de todo em PE?

(121) a. Então se [esse sistema de proteção $]_{i}$ ele $_{i}$ existe pode ter sido... PB b. Eu acho que [um trabalho $]_{i}$ ele $e_{i}$ teria que começar por aí.

Em Barbosa (1995) defendo que a teoria da adjunção faz ainda uma outra predição curiosa, já salientada e desenvolvida em Sola 1992. Em particular, prevê que possa haver redobro por um sujeito pronominal pósverbal. Recorde-se que, nesta teoria, os sujeitos argumentais ocupam a posição pós-verbal. Sendo assim, nada impede a derivação em que o DP está deslocado e o seu redobro não é o sujeito nulo mas sim um sujeito pósverbal. Com efeito, estas estruturas existem, tal como ilustrado em (122):

(122) a. A Teresa escreveu ela o poema, ninguém a ajudou.

b. A Teresa escreveu o poema ELA, ninguém a ajudou.

Exemplos semelhantes a (122a,b) ocorrem em espanhol, italiano, catalão e occitano (veja-se Sola 1992, Rigau 1987, Burzio 1986, Piera 1987) e são conhecidos na literatura como ilustrativos do uso de pronomes enfáticos. Assim, (122a,b) são sinónimas de 'Foi a Teresa que escreveu o poema', com foco exclusivo sobre o sujeito. A única diferença entre (122a) e (122b) reside na posição ocupada pelo pronome, antes ou depois do objecto. Quando o pronome ocorre a seguir ao objecto necessita de receber acento prosódico (cf. (122b).

A interpretação de (122a,b) não é surpreendente dada a leitura focalizada dos pronomes em posição pós-verbal. Assim, a mesma interpretação mantém-se quando retiramos o DP 'a Teresa' a (122):

(123) a. Escreveu ela o poema, ninguém a ajudou.

b. Escreveu o poema ELA, ninguém a ajudou.

= Foi ela que escreveu o poema, ninguém a ajudou.

O facto de, em (122) e (123), o pronome ser interpretado da mesma forma encaixa bem na teoria que assume que o sujeito pré-verbal em (122) está deslocado, sendo redobrado pelo sujeito pronominal. 
A teoria que defende que o sujeito em (122) está em Spec-IP não pode, em princípio, manter que o pronome ocupa uma posição argumental, na medida em que teríamos uma violação da condição B da teoria da ligação. É por isso que tem sido proposto que os pronomes enfáticos são anáforas em posição não argumental (Piera 1987) ou o spell out do vestígio do sujeito (Burzio 1986). Estas teorias, contudo, enfrentam o problema de este tipo de pronomes enfáticos apenas se verificar em LSN. Em inglês e francês, apenas as anáforas podem ocorrer nestes contextos:

(124) a. *John wrote the letter HE

b. John wrote the letter himself.

(125) a. *Jean l'a fait LUI.

b. Jean l'a fait lui-même.

A análise segundo a qual o pronome enfático é o spell out do vestígio do sujeito não tem nada a dizer acerca desta diferença entre as LSN e o francês e o inglês. Por outro lado, a análise que assume que estes pronomes são adjuntos enfrenta dois problemas. Em primeiro lugar, se estes pronomes são mesmo adjuntos, espera-se que possam ligar-se a um qualquer DP na frase, tal como sucede com a anáfora do inglês; contudo, não é isto que se verifica. Os pronomes enfáticos não podem aparecer ligados nem a sujeitos pós-verbais (cf. (126a), nem a objectos (cf. (126b)); neste caso, a forma anafórica complexa ela própria tem de ser usada (cf. (126c)):

(126) a. *Apareceu a presidente ELA.

b. *Falei com a presidente ELA

c. Apareceu a presidente ela própria.

Outra propriedade que distingue os pronomes enfáticos da anáfora complexa é o facto de serem orientados para o sujeito. Assim, o pronome enfático em (127a) só pode estabelecer uma relação anafórica com o sujeito; esta restrição não se aplica à anáfora complexa no PE (cf. (127b)) ou no inglês (cf. (128)):

(127) a. $[\text { A criança }]_{i}$ foi felicitada pel[a professora $]_{k}$ ELA $_{i / * k}$ b. $\{\text { A criança }]_{i}$ foi felicitada pel[a professora $]_{k}$ ela própria $_{i / k}$

(128) The girl was congratulated by [the teacher $]_{i}$ herself $_{i}$

É precisamente com base nestes factos que Barbosa 1995 conclui que os pronomes enfáticos não são adjuntos anafóricos e são antes um tipo particular de pronome anafórico característico das LSN. A sua presença 
decorre naturalmente da observação de que nada impede o sujeito nocional deslocado de se ligar por co-referiencia ao sujeito pronominal pós-verbal, tal como ilustrado em (129):

$$
\left.\mathrm{DP}_{\mathrm{i}} \mathrm{L}_{\mathrm{IP}} \mathrm{V} \operatorname{Pron}_{\mathrm{i}} \ldots\right]
$$

Convém salientar que a análise defendida por Costa pode também derivar a configuração em (129), uma vez que Costa admite a possibilidade da deslocação, mas, para tal, terá de reconhecer que, em todos os exemplos com pronomes enfáticos e um sujeito pré-verbal, o sujeito está deslocado, o que implica alargar a deslocação aos casos em que não se verifica qualquer pausa entoacional entre o sujeito e o resto da frase, perdendo-se assim a argumentação baseada na neutralidade prosódica e informacional da ordem SVO.

Dito isto, consideremos a primeira objecção de Costa, que passamos a citar:

(...) existem línguas românicas de sujeito nulo em que o redobro de um DP em posição pré-verbal por um pronome é obrigatória. Barbosa (1995) defende que esse comportamento é o esperado em línguas em que o DP pré-verbal é deslocado à esquerda. Em PE, embora o redobro do sujeito por um pronome não seja obrigatório, é possível. Por exemplo, em resposta a interrogativas múltiplas, o redobro do DP sujeito pelo pronome é opcionalmente aceitável (Costa 2000):
A: Quem leu o quê?
B: a. O João, ele leu o livro.
b. O João leu o livro.

Existem, contudo, contextos em que o redobro do DP por um pronome é agramatical. Por exemplo, em contextos em que toda a frase é focalizada, o redobro do sujeito por um pronome é bastante marginal:
A: $\mathrm{O}$ que é que aconteceu?
B: a. O João leu o livro.
b.??*O João, ele leu o livro.

A análise que assume que o sujeito pré-verbal está sempre deslocado à esquerda prediz que o redobro pelo pronome deverá ser sempre possível, em analogia com o que acontece nas línguas em que o redobro pelo pronome é obrigatório e independente de contexto. 
Espero que a introdução a esta secção tenha sido suficientemente clara para que se perceba que a análise da deslocação não prevê de forma nenhuma a produtividade de (19b), uma vez que prevê que este exemplo envolve deslocação múltipla com redobro por pro (cf. (119b)). Tal configuração, como é óbvio, não seria nada apropriada no contexto dado. As línguas a que Costa se refere são os dialectos italianos com sujeitos clíticos cuja presença é obrigatória. Poletto 1992 e Barbosa 1995, entre outros, defendem que os clíticos nestas línguas têm a mesma função da concordância em línguas como o PE ou o italiano padrão, i.e., identificam um sujeito nulo (pro) em posição argumental. Por conseguinte, as construções $\mathrm{SV}(\mathrm{O})$ do $\mathrm{PE}$ é que são as equivalentes das construções $\mathrm{S}-\mathrm{cl}-\mathrm{V}(\mathrm{O})$ nos dialectos. O pronome do $\mathrm{PE}$ nem é um clítico nem é obrigatório, portanto não é comparável às formas clíticas dos dialectos.

No que respeita ao contexto (18), parece-me que o que aí temos é, primeiro, a resposta relativa ao sujeito, "O João", ligada por parataxe à estrutura frásica com DEC de sujeito:

(130) O João ... ele leu o livro.

O segundo argumento de Costa prende-se com construções de redobro por parte de um sujeito pós-verbal. A seguir, citamos a passagem relevante (itálico nosso):

(21) a. O João, leu ele o livro.

b. O João, ele leu o livro.

Se a colocação pós-verbal do pronome não levanta problemas para a análise que pressupõe que o sujeito pré-verbal se encontra deslocado à esquerda, já a frase (21b) é problemática, uma vez que implica assumir que existe deslocação à esquerda de dois sujeitos. Note-se que não há problema em ter deslocação à esquerda do mesmo elemento, como em (22), em que o DP é redobrado pelo pronome forte a ele, que se encontra ele próprio deslocado à esquerda e pelo clítico:

O João, a ele, vi-o no cinema.

Contudo, se o clítico pode ocorrer, espera-se que quando co-ocorrem em posição pré-verbal o DP e o pronome ele, seja possível encontrar redobro pelo pronome em posição pós-verbal correspondente ao clítico de (22). No entanto, esta predição é infirmada: 
O João, ele leu (*ele) o livro.

Assumindo-se que o pronome pré-verbal se encontra em Spec,IP, espera-se que não seja possível encontrar outro sujeito numa posição mais baixa, dado que o sujeito que se encontra em Spec,IP terá sido deslocado de Spec,VP.

Recorde-se que a análise da deslocação atribui a (21b) a seguinte estrutura:

(131) O João [ ele [ leu pro o livro]]

Em (131) há dois elementos deslocados e uma forma pronominal em posição argumental, pro, identificada pelo afixo de concordância. Esta última é que é a forma correspondente ao pronome clítico; por conseguinte, a estrutura correspondente a (22) é (131), i.e., (21b) e não (23). É verdade que, na nossa perspectiva, há uma outra possibilidade para além de (21b), nomeadamente o redobro pela forma plena do pronome em posição pósverbal (21a), mas essa não é a forma correspondente a (22), com um clítico, porque os clíticos, tal como pro, não podem nunca ser focalizados.

Uma vez que entendo que exemplos como (21b) envolvem deslocação de dois DPs com o mesmo referente, sendo por isso redundantes, não vou construir exemplos semelhantes a (23), que são triplamente redundantes. Contudo, posso citar o exemplo que se segue, que me parece perfeitamente gramatical, em que há redobro de um pronome em posição pré-verbal por um pronome em posição pós-verbal:

(132) A filha da Maria é muito precoce. Olha que ela ontem à noite fez ela o jantar. $=$ Olha que ontem foi ela que fez o jantar.

É evidente que não vamos encontrar (132) na escrita, mas não tenho a mínima dúvida de que ocorre na fala. E este exemplo conduz-nos directamente ao último parágrafo da passagem transcrita, que pode ser usado exactamente para perguntar como explica então a análise tadicional este e outros exemplos com pronomes enfáticos e sujeitos pré-verbais (cf. (122) $)^{21}$.

21 É curioso verificar que Costa coloca estrategicamente uma vírgula no exemplo (21b), mas a vírgula não é necessária (cf. 122). 


\section{Conclusões}

Neste artigo, examinámos os argumentos de Costa contra a análise da deslocação e vimos que a maior parte deles assentam em pressupostos que não sobrevivem a um escrutínio mais apurado. Vimos que a argumentação baseada nas propriedades informacionais e prosódicas da DEC de objecto não tem valor de prova, dadas as diferenças independentemente verificadas entre os dois tipos de deslocação a esse respeito. Para além disso, observámos ainda que não há incompatibilidade entre a análise da deslocação e o carácter informacionalmente neutro da ordem SVO.

Perante isto, dos onze contra-argumentos apresentados por Costa, apenas um constitui um verdadeiro desafio a esta teoria, nomeadamente as diferenças posicionais entre a DEC de objecto e as construções com sujeitos pré-verbais em interrogativas e relativas. Contudo, também este argumento não sobrevive a um estudo mais atento, dado que os dativos que correspondem ao argumento mais alto (ou os sujeitos em línguas com redobro pronominal visível como o francês) podem ocorrer em DEC nesses mesmos contextos, no que se distinguem dos argumentos mais "baixos" (objectos ou outro tipo de dativos).

Ao longo deste trabalho, vimos também que, apesar de a análise da deslocação parecer, à partida, contra-intuitiva, tem a enorme vantagem de se integrar numa teoria do Parâmetro do Sujeito Nulo, que, sendo extremamente simples, tem um alcance empírico considerável. Em particular, é capaz de predizer não só o leque de propriedades classicamente atribuídas às LSN como uma série de outras que, à partida, nenhuma outra teoria é capaz de prever. Por razões de espaço, não nos foi possível referir todo o domínio empírico alcançado, mas remetemos o leitor interessado para os textos em que esse trabalho é desenvolvido (Barbosa 1995, 1996b, 2001, 2002 e Barbosa, I. D. Duarte e Kato (2001, 2006).

A teoria que defende que os sujeitos ocupam a posição canónica, por outro lado, está de acordo com as nossas intuições de que a ordem SVO é a ordem mais neutra do ponto de vista informacional, mas tem uma capacidade preditiva pobre e necessita de uma série de assunções adicionais para lidar com os fenómenos referidos neste artigo e nos trabalhos citados. A opção entre uma e outra teoria depende, em última análise, do peso que damos a cada um destes factores. 
Corpora citados:

Dicionário de Combinatórias do Português (DCP), Corpus de Referência do Português Contemporâneo, (CRPC), Centro de Linguística da Universidade de Lisboa.

Português Fundamental, Corpus de Referência do Português Contemporâneo, (CRPC) Centro de Linguística da Universidade de Lisboa.

Recebido em junho de 2005

Aprovado em agosto de 2005

Versão reformulada em abril de 2006

E-mail: pbarbosa@ilch.uminho.pt

\section{REFERÊNCIAS}

Alexiadou, A. e E. Anagnostopoulou. 1998. Parametrizing AGR: Word Order, V-Movement and EPP-Checking. NLLT 16: 491-539.

Ambar, M. 1988. Para uma Sintaxe da Inversão Sujeito Verbo em Português, $\mathrm{PhD}$. diss., University of Lisbon, Lisbon.

. 1998. Word order effects of a split CP hypothesis. Comunicação apresentada na workshop Inversion in Romance, University of Amsterdam, May 1998.

Baker, M. 2003. Agreement, Dislocation and Partial Configurationality. In A. Carnie, H. Harley e M. Willie (eds.), Formal Approaches to Function Grammar. John Benjamins.

Barbosa, P. 1993. Clitic Placement in Old Romance and European Portuguese, CLS 29: Papers from the Twenty-Ninth Regional Meeting of the Chicago Linguistic Society, Chicago.

. 1994. "A New Look at the Null Subject Parameter". Comunicação apresentada no encontro ConSOLE IV Meeting, University of Venice. . 1995. Null Subjects, PhD. dissertation. MIT, Cambridge, Mass. 1996a. Clitic placement in European Portuguese and the position of subjects. Approaching second: Second position clitics and related phenomena. ed. by A. Halpern \& A. Zwicky, 1. CSLI Publications, Stanford, California.

. 1996b. A new Look at the Null Subject Parameter. Proceedings of ConSole IV, ed. by J. Costa, R. Goedemans \& Ruben van de Vijver, Leiden, The Netherlands. 
. 2000. Clitics: a Window into the Null Subject Property. In João Costa (org.) Essays in Portuguese Comparative Syntax. New York: Oxford Press.

. 2001."On Inversion in Wh-questions in Romance". In A. Hulk \& J.-Y. Pollock (orgs.), Romance Inversion. New York: Oxford Press.

. Kato, M. \& Duarte, M. E. 2001. 'A Distribuição do Sujeito Nulo no Português Europeu e no Português do Brasil'. Actas do 24 Encontro da APL. Coimbra.

. 2002. "O PPA e a Propriedade do Sujeito Nulo". In Clara Nunes (org.) Volume de Homenagem a Henriqueta Costa Campos. Lisboa: Universidade Nova de Lisboa.

. Kato, M. \& Duarte, M. E. (no prelo) 'Null Subjects in European and Brazilian Portuguese'. Journal of Portuguese Linguistics. Lisboa: Colibri.

Beghelli, F. e Tim Stowell. 1997. Distributivity and Negation. The Syntax of Each and Every. In A. Szabolcsi (ed.) Ways of Scope Taking. Dordrecht: Kluwer.

Belleti, A. 1990. Generalized Verb Movement. Rosenberg \& Sellier, Torino. Bonet, E. 1990. Subjects in Catalan. MIT Working Papers 13, 1. Cambridge, Mass.

Brito, A. and Duarte, I. 1983. "Condições sobre Posposição do Sujeito em Português.” Boletim de Filologia, Tomo 27: 191-254. Lisboa: Centro de Lingüística da Universidade de Lisboa.

Burzio, L. 1986. Italian syntax. Reidel, Dordrecht.

Calabrese, A. 1990. "Some Remarks on Focus and Logical Structures in

Italian." Harvard Working Papers in Linguistics. Cambridge: Harvard University.

Campos, H. 1997. "On Subject Extraction and the Antiagreement Effect in Romance." Linguistic Inquiry 28: 92-119.

Chomsky, N. 1977. "On wh-Movement." In P. Culicover, T. Wasos and A. Akmajian (eds.) Formal Syntax 71-132. New-York: Academic Press. . 1999. Derivation by Phase. MITWPL nº 18 . Cambridge, MA.

Chомsкy, Noam. 2004. Beyond explanatory adequacy. Belletti, Adriana (ed.) Structures and Beyond. The Cartography of Syntactic Structures. Volume 3. New York: Oxford University Press.

Cinque, G. 1990. Types of $A^{\prime}$-dependencies. The MIT Press, Cambridge.

Contreras, H. 1991. On the position of subjects. Syntax and Semantics, 25. Academic Press. 
Costa, J. 1996. Positions for subjects in European Portuguese. Proceedings of WCCFL XV, CSLI, Stanford.

. 1998. Word Order Variation. A Constraint-based Approach. Dissertação de Doutoramento. Universidade de Leiden, The Netherlands. . 2000. SVO vs. VSO in multiple-focus context. Ms. Universidade Nova de Lisboa.

. 2001. Spec-IP ou deslocado? Prós e contras das duas análises dos sujeitos pré-verbais. In DELTA 17, n². S. Paulo: EDUC.

. 2004. Subject Positions and Interfaces: The Case of European Portuguese, Studies in Generative Grammar 73, Mouton de Gruyter, Berlin.

Costa, J. \& I. Duarte. 2002. Preverbal sbjects in null subject languages are not necessarily dislocated. Journal of Portuguese Linguistics 2: 159176. Lisboa: Colibri.

Costa, J. \& Ana Maria Martins. 2003. Clitic placement across grammar components. Comunicação apresentada no Encontro Going Romance 2003. Nijmegen, 20-22 November.

Costa, J. \& S. Pereira. 2005. 'Phases and autonomous features: a case of mixed agreement in European Portuguese'. MIT Workink Papers in Linguistics, ed. by Martha McGinnis and Norvin Richards. Cambridge, Mass: Massachusetts Institute of Technology.

Dobrovie-Sorin, C. 1994. The syntax of Roumanian: Comparative studies in Romance. Foris, Dordrecht.

DuArte, Maria Eugenia.l. 1993. "Do pronome nulo ao pronome pleno" In: I. Roberts \& M. A Kato (eds.) Português Brasileiro: Uma viagem diacrônica (Homenagem a Fernando Tarallo). Campinas: Editora da UNICAMP: 107-128.

. 1995. A Perda do Princípio "Evite pronome" no Português Brasileiro. UNICAMP: Doctoral Dissertation.

Duarte, I. 1987. A construção de Topicalização na Gramática do Português: Regência, Ligação e Condições sobre Movimento, $\mathrm{PhD}$. diss., University of Lisbon, Lisbon.

. 1997. Ordem de Palavras e Estrutura Discursiva. In A. M. Brito, F. Oliveira, I. Pires de Lima \& R. M. Martelo (orgs.) Sentido que a Vida Faz - Estudos para Óscar Lopes. Porto: Campo das Letras. . 2003. In Maria Helena Mateus, Ana Maria Brito, Inês Duarte, Isabel Hub Faria et alii. Gramática da Língua Portuguesa. Lisboa: Caminho. 
Frota, S. and M. Vigário. 1996. "On Weight Effects in European Portuguese." Talk presented at the GLOW Workshop on Weight Effects, Athens.

Grimshaw, J. \& SAmeK-Lodovici. 1998. Optimal subjects. In P. Barbosa, D. Fox, P. Hagstrom M. McGinnis and D. Pesetsky (eds.) Is the Best Good Enough? Optimality and Competition in Syntax. Cambridge: MIT Press.

Guéron, Jacqueline. 1980. 'On the Syntax and Semantics of PP Extraposition. Linguistic Inquiry 11-4.

IATRIDou, S. 1991. Clitics and island effects. [Ms., MIT]

JAEGGLI, O. 1984. Subject extraction and the null subject parameter. NELS 14.

Jaeggli, O. \& SAfiR, K. 1989. (eds.) The Null Subject Parameter. Kluwer Academic Publishers.

Kato, M. A. 1999. Strong and Weak Pronominals in the Null Subject

Parameter. Probus 11, 1-37. The Netherlands: Walter de Gruyter.

Klima, E. 1964. Negation in English. In J. Katz and J. Fodor (eds.) The Structure of Language (Prentice-Hall).

LASNiK, H. \& M. SAIto. 1992. Move a. Conditions on Its application and Output. Cambridge: MIT Press.

Longobardi, G. 2000. 'Postverbal' Subjects and the Mapping Hypothesis. Linguistic Inquiry, 31, n¹/4 4: 691-702.

Martins, Ana Maria. 1994. Clíticos na História do Português. Ph.D. Dissertation. Universidade de Lisboa.

Matos G. 1992. Construções de elipse do predicado em Português. SV Nulo e Despojamento. Tese de Doutoramento. Universidade de Lisboa. Montalbetti, M. 1986. How pro is it? Studies in Romance Llnguistics. Foris, Dordrecht, ed. by O. Jaeggli, 137.

Ordónez, F. 1995. Post-verbal asymmetries in Spanish. NLLT 16: 313-346.

Pesetsky, D. 1989. Language-particular processes and the Earliness Principle. Ms., MIT, Cambridge, Mass.

Piera, C. 1987. Sobre la estructura de las cláusulas de infinitivo. In V. Demonte \& M. Lagunilla (orgs.) Sintaxis de las Lenguas Románicas. 148-163. Madrid: Ediciones El Arquero.

Pinto, M. 1994. Subjects in Italian: Distribution and Interpretation. In R. Bok-Bennema and C. Cremers (eds.) Linguistics in the Netherlands. Amsterdam/Philadelphia: John Benjamins Publishing Company. 
Pollock, A. 1990. Verb Movement, Universal Grammar and the Structure of IP. LI 20: 365-424.

Pollock, J.-Y. 1997. Langage et Cognition: Introduction au Programme Minimaliste de la Grammaire Générative. Paris: Presses Universitaires de France.

Poletto, C. 1992. La Sintassi del Soggetto nei Dialetti Italiani Settentrionali, Quaderni Patavini di Linguistica, Monografie. 12.

Raposo, Eduardo. 1994. Affective Operators and Clausal Structure in European Portuguese and European Spanish. Ms., University of California at Santa Barbara, Calif.

. 1996. 'Definite/Zero Alternations in Portuguese: Towards a Unification of Topic Constructions'. In A. Schwegler, B. Tranel and M. Uribe-EtXebarria (eds.) Romance Linguistics: Theoretical Perspectives. Amsterdam: John Benjamins Co.:197-212.

e Juan Uriagereka. 2005. Clitic Placement in Western Iberian: A Minimalist View. In G. CinQue and R. KaYne (eds.) The Oxford Handbook of Comparative Syntax. Oxford: Oxford University Press: 639-697. REINHART, T. 1995. Interface strategies. [Ms. OTS/Utrecht University.] Rigau, G. 1987. "Sobre el Carácter Quantificador de los Pronombres Tónicos en Catalán.” In Violeta Demonte and Marina Fernández Lagunilla (eds.) Sintaxis de las lenguas Románicas. Madrid: Textos Universitarios. Rizzi, L. 1982. Issues in Italian Syntax. Dordrecht: Kluwer. Kluwer Academic Publishers.

. 1986. Null Objects in Italian and the Theory of pro. Linguistic Inquiry 17: 501-557.

. 1997. The Fine Structure of the Left Periphery. In L. Haegeman (ed.) Elements of Grammar. Dordrecht: Kluwer.

SAmeK-Lodovici, V. 1994. "Structural Focusing and Subject Inversion in Italian." Trabalho apresentado em Linguistics Symposium on Romance Languages XXIV. Los Angeles.

Saccon, G. 1993. Post-verbal Subjects: A Study Based on Italian and its Dialects. Ph.D. Dissertation. Harvard University.

Silva, M. Cristina F. 1996. A Posição do Sujeito no Português Brasileiro. Frases Finitas e Infinitivas. Campinas: Editora da Unicamp.

SolA, J. 1992. Agreement and Subjects. Dissertação de Doutoramento. Universitat Autònoma de Barcelona.

Torrego, E. 1984. On inversion in Spanish and some of its effects. LI 15, 103-129. 
UriagerekA, J. 1995a. "Aspects of the Syntax of Clitic Placement in Western Romance." LI 26, 79-123.

Uribe-ETxebarria, M. 1991. On the structural positions of the subject in Spanish, their nature and their consequences for quantification. [Ms., Univ. of Connecticut.]

Vallduví, E. 1990. The Informational Component. Ph.D. dissertation. University of Pennsylvania. . 1992. "A Preverbal Landing Site for Quantificational Operators."

In Catalan Working Papers in Linguistics 1992: 319-344. Barcelona: Universitat Autònoma de Barcelona.

Zubizarreta, M. L. 1998. Word Order, Prosody and Focus. Cambridge: MIT Press.

Williams, E. 1980. Predication. LI 11: 203-238. Cambridge: MIT Press. 